\title{
Comparison of the Functional microRNA Expression in Immune Cell Subsets of Neonates and Adults
}

\author{
Hong-Ren Yu' ${ }^{1 *}$, Te-Yao Hsu' ${ }^{2}$, Hsin-Chun Huang ${ }^{1}$, Ho-Chang Kuo', Sung-Chou Li ${ }^{3}$, \\ Kuender D. Yang ${ }^{4,5,6}$ and Kai-Sheng Hsieh ${ }^{1}$
}

'Department of Pediatrics, Chang Gung Memorial Hospital-Kaohsiung Medical Center, Graduate Institute of Clinical Medical Science, Chang Gung University College of Medicine, Kaohsiung, Taiwan, ${ }^{2}$ Department of Obstetrics, Chang Gung Memorial Hospital-Kaohsiung Medical Center, Graduate Institute of Clinical Medical Science, Chang Gung University College of Medicine, Kaohsiung, Taiwan, ${ }^{3}$ Genomics and Proteomics Core Laboratory, Chang Gung Memorial Hospital-Kaohsiung Medical Center, Graduate Institute of Clinical Medical Science, Chang Gung University College of Medicine, Kaohsiung, Taiwan, ${ }^{4}$ Institute of Biomedical Sciences, Mackay Medical College, New Taipei City, Taiwan, ${ }^{5}$ Department of Pediatrics, Mackay Memorial Hospital, Taipei, Taiwan, ${ }^{6}$ Institute of Clinical Medicine, National Yang Ming University, Taipei, Taiwan

OPEN ACCESS

Edited by: James Lawrence Wynn, University of Florida, USA

Reviewed by: Jiu-Yao Wang, National Cheng Kung University, Taiwan

Alessandro Laganà, Icahn School of Medicine at Mount Sinai, USA

Romina Jimena Fernandez-Brando, IMEX-CONICET-ANM, Argentina

*Correspondence: Hong-Ren Yu yuu2004taiwan@yahoo.com.tw

Specialty section:

This article was submitted to Microbial Immunology,

a section of the journal

Frontiers in Immunology

Received: 13 July 2016 Accepted: 05 December 2016 Published: 19 December 2016

Citation:

Yu H-R, Hsu T-Y, Huang H-C, Kuo H-C, Li S-C, Yang KD and Hsieh K-S (2016) Comparison of the Functional microRNA Expression in Immune Cell Subsets of Neonates and Adults.

Front. Immunol. 7:615. doi: 10.3389/fimmu.2016.00615
Diversity of biological molecules in newborn and adult immune cells contributes to differences in cell function and atopic properties. Micro RNAs (miRNAs) are reported to involve in the regulation of immune system. Therefore, determining the miRNA expression profile of leukocyte subpopulations is important for understanding immune system regulation. In order to explore the unique miRNA profiling that contribute to altered immune in neonates, we comprehensively analyzed the functional miRNA signatures of eight leukocyte subsets (polymorphonuclear cells, monocytes, CD4 ${ }^{+} \mathrm{T}$ cells, CD8 ${ }^{+} \mathrm{T}$ cells, natural killer cells, B cells, plasmacytoid dendritic cells, and myeloid dendritic cells) from both neonatal and adult umbilical cord and peripheral blood samples, respectively. We observed distinct miRNA profiles between adult and neonatal blood leukocyte subsets, including unique miRNA signatures for each cell lineage. Leukocyte miRNA signatures were altered after stimulation. Adult peripheral leukocytes had higher let-7b-5p expression levels compared to neonatal cord leukocytes across multiple subsets, irrespective of stimulation. Transfecting neonatal monocytes with a let-7b-5p mimic resulted in a reduction of LPS-induced interleukin (IL)- 6 and TNF- $\alpha$ production, while transfection of a let-7b-5p inhibitor into adult monocytes enhanced IL-6 and TNF- $\alpha$ production. With this functional approach, we provide intact differential miRNA expression profiling of specific immune cell subsets between neonates and adults. These studies serve as a basis to further understand the altered immune response observed in neonates and advance the development of therapeutic strategies.

Keywords: microRNA, cord blood, leukocyte subsets, let-7b, monocytes

\section{INTRODUCTION}

Differences in the expression of biological molecules in the immune cells of newborns and adults contribute to diverse cell function and atopic properties (1-5). These immune differences are reflected in varied immune responses, cellular subset composition, cytokine production, and cellular/humoral protein levels $(3,4,6,7)$. Other mediators including interleukin (IL)-10, 
prostaglandin E2, and progesterone produced by the placenta can also upregulate Th2 differentiation, resulting in downregulation of Th1 responses (8-10). In the previous studies, we found that neonates have selectively impaired IFN $\alpha$-mediated Th1 immune responses $(3,11)$. By using proteomic tools, we identified at least 34 differentially expressed proteins between adult peripheral blood mononuclear cells (PBMCs) and cord blood mononuclear cells (CBMCs). There were also validated cytoskeletal differences between PBMCs and CBMCs (12). Moreover, we observed a decrease in adenosine deaminase and an increase in arginase-1 in neonatal mononuclear cells (MNCs), which was associated with impaired immune function (6). Different modulatory effects of adenosine and $\mathrm{L}$-arginine on neonatal and adult leukocytes have also been investigated (4).

microRNAs (miRNAs) are small (19-22 nt) single-stranded non-coding RNA molecules derived from hairpin-structured precursors (13). These miRNAs function by directly binding to the indicated 3 '-untranslated region of specific target mRNA, leading to target mRNA degradation or translational repression. miRNAs have been shown to play important roles in human development, cellular differentiation and homeostasis, adaptation, oncogenesis, and host cell interactions with pathogens (14-16). miRNAs are also involved in the regulation of immune systems, indicating that they modulate many aspects of the immune response, such as differentiation, proliferation, and activation of intracellular signaling pathways (17-19).

Recently, the essential regulatory roles of specific miRNAs in neonatal immune responses have also been noted. miR-184 was reported to regulate NFAT1 in neonatal CD4 T cells (20), while miR-146a and miR-155 downregulated toll-like receptor (TLR) signals in neonatal monocytes and plasmacytoid dendritic cells (pDCs), respectively $(21,22)$. We also found that miR-125b negatively regulates LPS-induced TNF- $\alpha$ expression in neonatal monocytes (23). It is possible that there is greater diversity in miRNA expression in neonatal leukocytes, which may contribute to the unique immunity of neonates.

Accumulating evidence demonstrates that miRNAs show specific signatures in different blood cell lineages and various stages of cellular differentiation (24-26). Since different cell types have unique functions and correspondingly, distinct gene expression profiles, determining the specificity of miRNA expression profiles in different leukocyte subpopulations is very important for both understanding the biology of the immune system and for characterization. Our hypothesis is that distinct miRNA profiles of different leukocyte subpopulations from neonatal and adult samples contribute to their relatively different immune responses. To exhibit proper immune functions, the immune cells must undergo activation, proliferation, and cytokine production upon encountering antigens (27). The miRNA profiles of leukocytes from neonates and adults have been widely reported. However, an important limitation of these studies was that they did not directly compare activated leukocytes of cord blood (CB) with those from adult peripheral blood, but instead used resting leukocytes. This approach is not as informative for identifying true differences in the functional transcriptome. In other studies, total leukocytes were investigated rather than unique leukocyte subsets (28). This approach is also information limiting because leukocyte subsets have distinct functions. In this study, we set out to comprehensively analyze the miRNA expression signatures of eight leukocyte subsets [polymorphonuclear cells (PMNs), monocytes, $\mathrm{CD} 4^{+} \mathrm{T}$ cells, $\mathrm{CD} 8^{+} \mathrm{T}$ cells natural killer $(\mathrm{NK})$ cells, $\mathrm{B}$ cells, pDCs, and myeloid dendritic cells (mDCs)] between neonatal and adult samples. The miRNA profile of activated and resting leukocytes was also analyzed. With this functional approach, we provide differential miRNA expression profiling of specific immune cell subsets between neonates and adults. This provides a basis for further understanding of the altered immune response in neonates and can guide the development of novel therapeutic strategies.

\section{MATERIALS AND METHODS}

\section{Collection of Human Umbilical Cord Blood and Adult Peripheral Blood and Cell Separation}

Human umbilical CB was collected in heparinized tubes (10 U/ $\mathrm{ml}$ ) by cordocentesis at the time of elective Cesarean section or normal spontaneous delivery of healthy mothers, following the receipt of informed consent. About 20-50 ml of CB was obtained from each case. The peripheral blood samples were obtained from healthy adult volunteers aged 20-40 years. Approximately 50-100 $\mathrm{ml}$ of blood was obtained from each healthy adult depending on the experimental design. Heparinized blood samples were collected, and the plasma was stored at $-80^{\circ} \mathrm{C}$ before analysis. The leukocyte separation protocol was utilized as previously described $(11,12)$. Briefly, whole blood was mixed with 4.5\% (w/v) dextran (Amersham Pharmacia Biotech, Uppsala, Sweden) sedimentation at a ratio of 1:5 to separate leukocytes from red blood cells (RBCs) for $30 \mathrm{~min}$. Leukocytes were then separated into PMNs and MNCs by density gradient centrifugation in Ficoll-Plaque ${ }^{\mathrm{TM}}$ (Amersham Pharmacia) at a ratio of $2: 1$ at $1,500 \mathrm{rpm}$ for $30 \mathrm{~min}$ at $20^{\circ} \mathrm{C}$. After centrifugation over a Ficoll cushion, MNCs were washed and counted on a hemocytometer by trypan blue staining. The PMN fraction in MNCs was less than $1 \%$ in adult and neonate samples. The study protocol was approved by the institutional review board of the study hospital.

\section{Cell Separation and Enrichment}

$\mathrm{CD}^{+}$T-cells, CD8 ${ }^{+} \mathrm{T}$-cells, CD $14^{+}$monocytes, or CD56 ${ }^{+} \mathrm{NK}$ cells were separated from MNCs using the IMag Cell Separation Systems (BD Biosciences, San Jose, CA, USA) following the protocol supplied by the manufacturer. In brief, per $2 \times 10^{7}$ of MNCs pellet was suspended in $100 \mu$ of anti-human CD4, CD8, CD14, or CD56 magnetic particles (BD Biosciences) and incubated at room temperature for $30 \mathrm{~min}$. Then, the labeled cells were resuspended in $1 \times \mathrm{BD}_{\mathrm{IMag}}^{\mathrm{TM}}$ buffer, and the tubes were placed in the BD Imagnet ${ }^{\mathrm{TM}}$ (BD Biosciences) for $10 \mathrm{~min}$. With the tube in the BD IMagnet ${ }^{\mathrm{TM}}$, the supernatant was removed to discard the undesired leukocytes. To maximize purity, the 
process was repeated three times. Then, the indicated cell fraction was carefully washed and suspended in PBS or medium. For pDCs isolation, dead cells were initially depleted by magnetic negative selection with Dead Cell Removal Kit (Miltenyi. Biotec, Bergisch Gladbach, Germany), then per $5 \times 10^{7}$ of MNCs pellet was isolated with $50 \mu \mathrm{l}$ of CD304 (BDCA-4)-microbeads (Miltenyi Biotech) and magnetic columns according to the manufacturer's instructions. The mDCs were isolated by magnetic positive selection with CD1c (BDCA-1)-microbeads and a magnetic column (Miltenyi Biotech) following the depletion of CD $19^{+}$cells. The purity of isolated cells was confirmed by flow cytometry, and all isolated cells demonstrated greater than $90 \%$ purity (12).

\section{Cell Culture and Stimulation}

Approximately $1 \mathrm{ml}$ of leukocytes $\left(2 \times 10^{6}\right.$ cells $\left./ \mathrm{ml}\right)$ suspended in RPMI-1640 medium containing 10\% heat-inactivated fetal bovine serum were co-cultured with and without the indicated
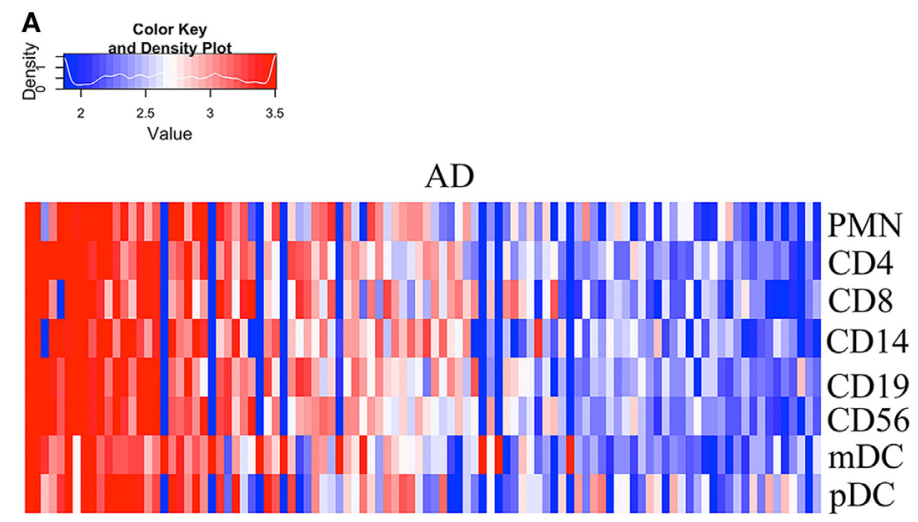

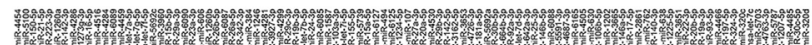

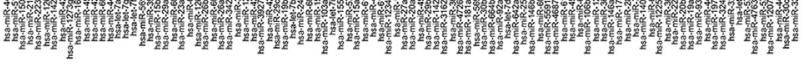

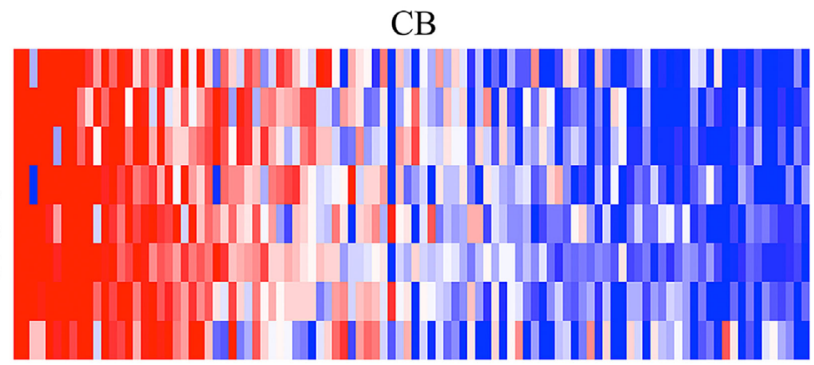

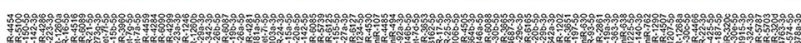

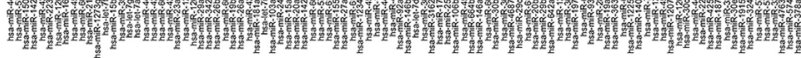

B
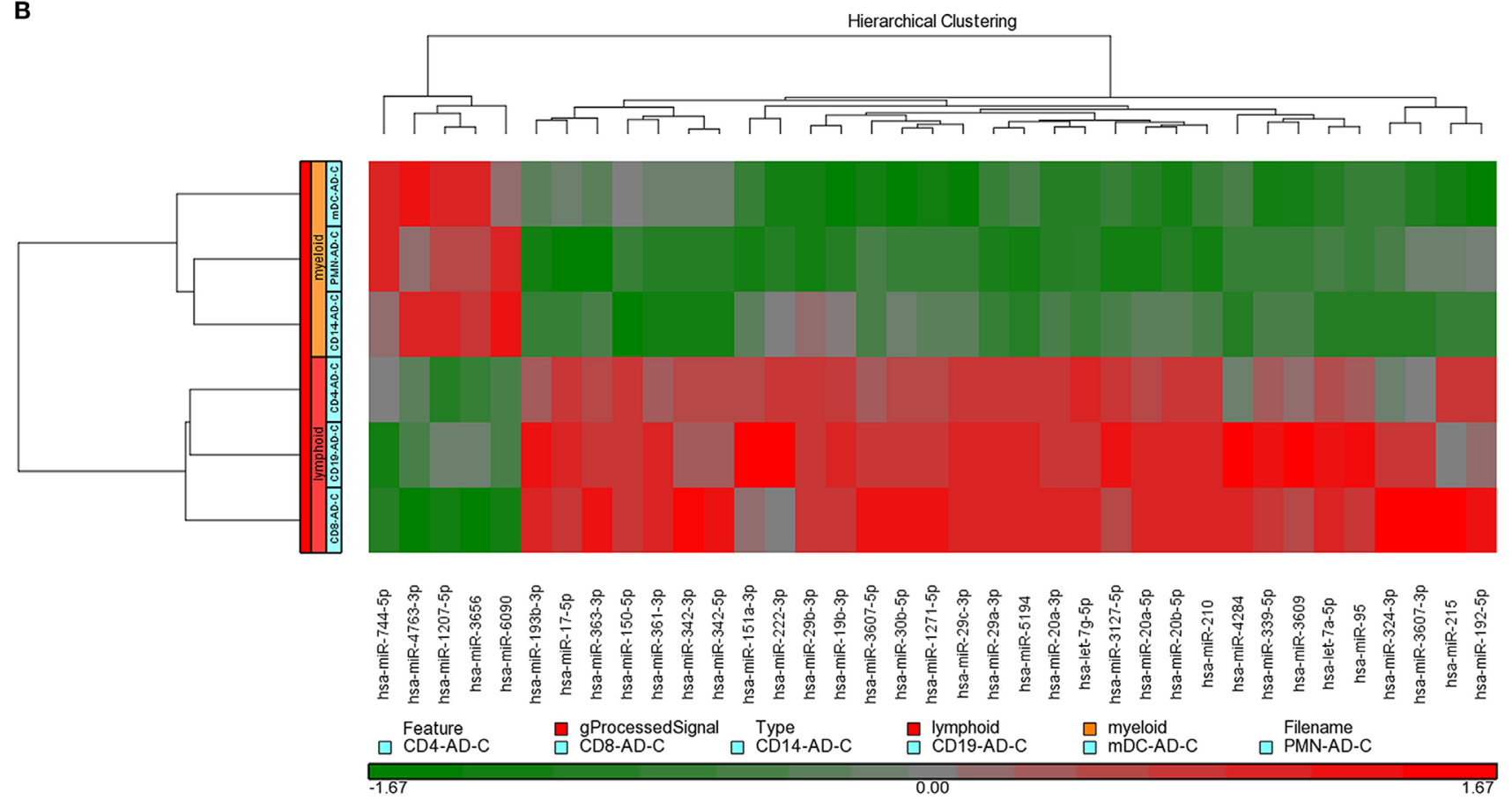

FIGURE 1 | Distinct microRNA (miRNA) expression between adult and neonatal leukocytes. (A) Neonate leukocyte subsets show distinct miRNA expression compared to adult leukocytes. Heat map showing distinct expression of miRNAs from different leukocyte subsets of adult peripheral blood (left) and cord blood (right). Each heat map lane represents the top 100 expressed miRNAs in each leukocyte subset. Higher intensity is shown in red and lower intensity in blue. (B) Myeloid and lymphoid leukocytes have unique miRNA profiles. Heat map showing distinct expression of miRNAs from myeloid (polymorphonuclear cells, CD14+ monocytes, and myeloid dendritic cells) and lymphoid (CD4+ T cells, CD8 ${ }^{+} T$ cells, and CD19+ B-cells) leukocyte subsets. Thirty-seven miRNAs with the highest transcript levels across all tested cell lineages were shown. Higher intensity is shown in red and lower intensity in green. 
stimulatory agents in 24-well culture plates. The cells were incubated in a humidified atmosphere of $5 \% \mathrm{CO}_{2}$ at $37^{\circ} \mathrm{C}$. PMNs, monocytes, and mDCs were stimulated with LPS (100 ng/ $\mathrm{ml}$ ) for $6 \mathrm{~h}$ and $\mathrm{CD}^{+}$and $\mathrm{CD}^{+} \mathrm{T}$ cells, B-cells, and NK cells were stimulated with PHA $(5 \mu \mathrm{g} / \mathrm{ml})$ for $24 \mathrm{~h}$. The stimulation condition for pDCs was CpG-ODN 2,216 (5 $\mu \mathrm{g} / \mathrm{ml})$ for $16 \mathrm{~h}$ as previously reported (29). Cells were harvested after culture and subjected to miRNA expression analysis.

\section{RNA Isolation}

Total RNA was extracted using the TRIzol ${ }^{\circledR}$ Reagent (Invitrogen, USA) according to the manufacturer's instructions. Purified RNA was quantified at OD260 nm using a ND-1000 spectrophotometer (Nanodrop Technology, USA) and qualitatively analyzed using a Bioanalyzer 2100 (Agilent Technology, USA) with RNA 6000 nano lab-chip kit (Agilent Technologies, USA).

\section{RNA Labeling and Hybridization}

Total RNA $(0.1 \mu \mathrm{g})$ was dephosphorylated and labeled with pCp-Cy3 using the Agilent miRNA Complete Labeling and Hyb Kit (Agilent Technologies, USA, microRNA Spike-In Apply). Hybridization buffer $(2 \times)$ (Agilent Technologies, USA) was added to the labeled mixture at a final volume of $45 \mu \mathrm{l}$. The mixture was heated for $5 \mathrm{~min}$ at $100^{\circ} \mathrm{C}$ and immediately cooled to $0^{\circ} \mathrm{C}$. Each $45 \mu \mathrm{l}$ sample was hybridized onto an Agilent human miRNA Microarray R19 (Agilent Technologies, USA) at $55^{\circ} \mathrm{C}$ for $20 \mathrm{~h}$. After hybridization, slides were washed for $5 \mathrm{~min}$ in Gene Expression Wash Buffer 1 at room temperature and then washed for $5 \mathrm{~min}$ in Gene Expression Wash Buffer 2 at $37^{\circ} \mathrm{C}$. Microarrays were scanned using the Agilent microarray scanner (Agilent Technologies, model G2505C) at $535 \mathrm{~nm}$ for Cy3. Feature Extraction (Agilent Technologies) software version 10.7.3.1 was used for image analysis. If both channels produced intensities less than 100 for a given miRNA, that spot was filtered out. For spots with one channel intensity less than 100 and the other 100 or greater, the signal that was less than 100 was set to 100 prior to calculation of the signal ratio. Hierarchical clustering was performed using the Genesis software (Graz University of Technology), and Pearson's correlation was calculated as the distance metric.

\section{miRNA Array}

In this study, we used Agilent SurePrint Human miRNA Microarray chips (Release 19.0, Agilent Technologies, Santa Clara, CA, USA) to globally evaluate the miRNA expression

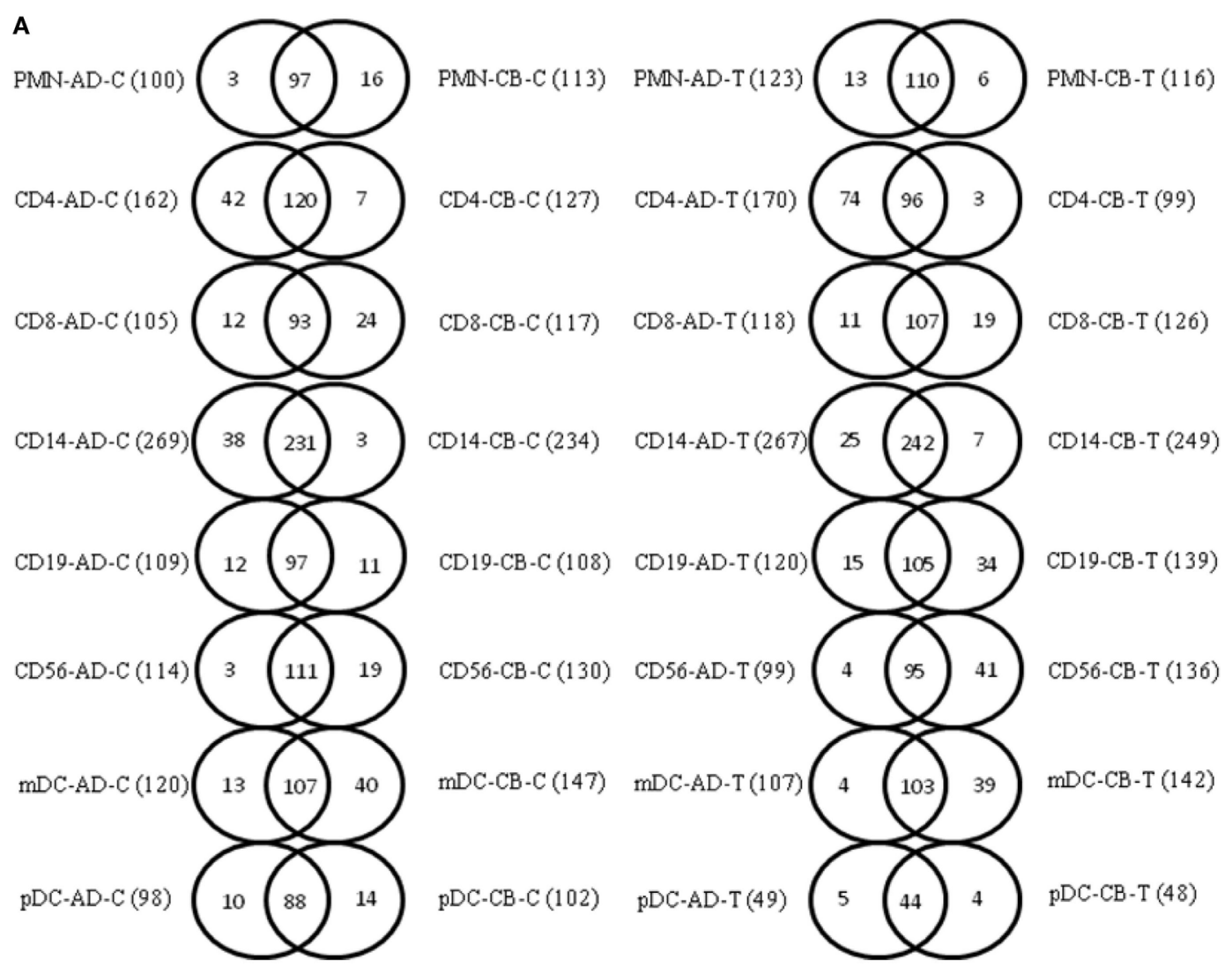

FIGURE 2 | Common and unique microRNA (miRNA) transcripts exist in adult and neonatal leukocyte subsets. 


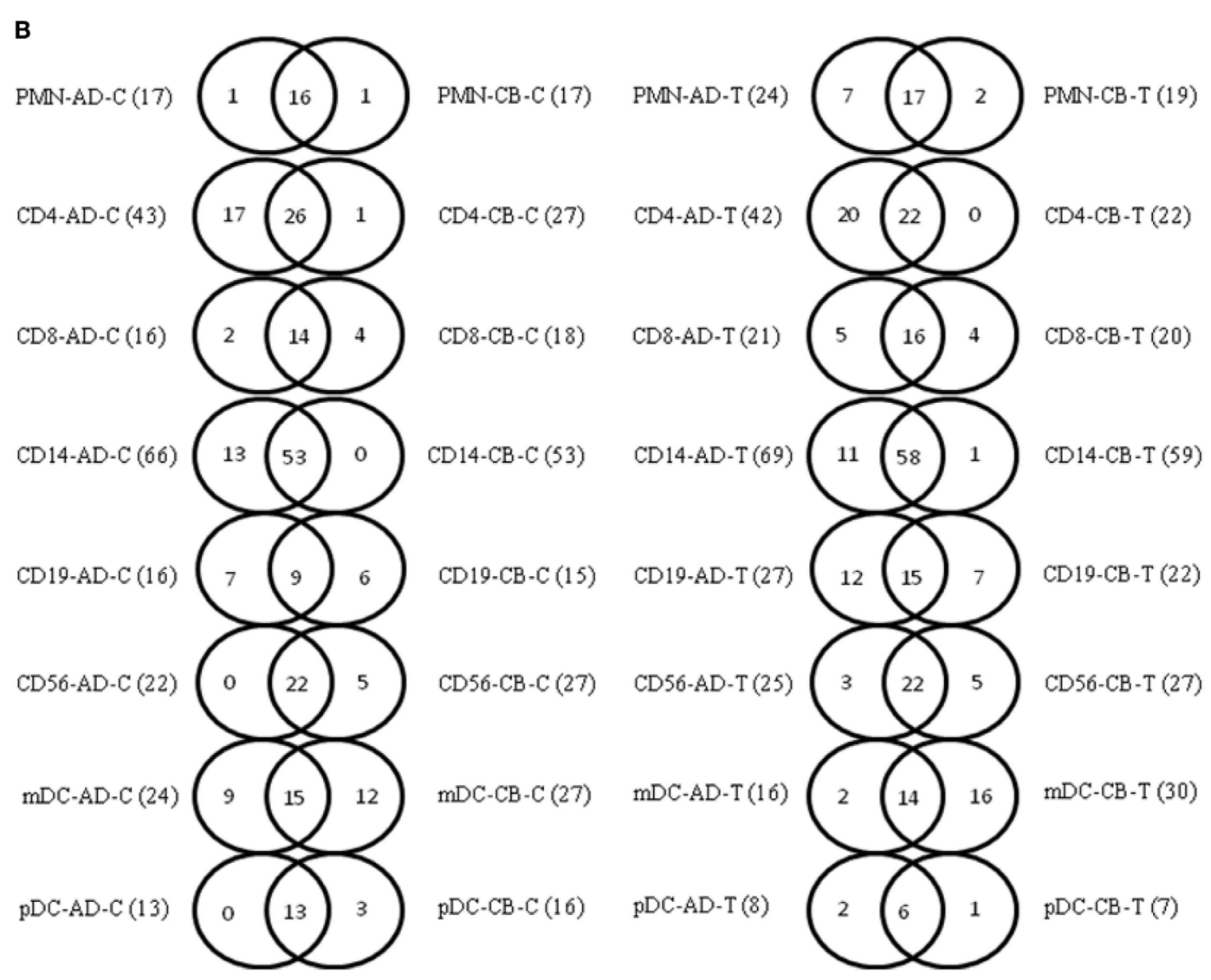

FIGURE 2 | Continued

(A) Venn diagrams showing comparative analysis of common and unique miRNA transcripts in the corresponding adult and cord blood (CB) leukocyte subsets (array intensity log 2 greater than 6). (B) Venn diagrams showing comparative analysis of common and unique miRNA transcripts in the corresponding adult and CB leukocyte subsets (array intensity log 2 greater than 10). Abbreviations: AD-C, adult blood cells without stimulation; CB-C, cord blood cells without stimulation; AD-T, adult blood cells with stimulation; CB-T, cord blood cells with stimulation.

profiles of the samples. The extracted RNA samples were first subjected to quality examination with a Bioanalyzer to check whether they passed the criterion, RIN $\geq 7.0$. Then, $0.5 \mu \mathrm{g}$ of the qualified RNA samples were prepared using the Agilent SurePrint Human miRNA Microarray kits, followed by microarray chip assays. The generated microarray data were analyzed with Partek (Partek Inc., St. Louis, MO, USA) under quantized normalization and $\log 2$ transformation. Total 32 miRNA array chips were used for 8 kinds of leukocytes with/without indicated stimulation from $\mathrm{CB}$ and adult peripheral blood.

\section{Quantitative Reverse Transcription PCR (qRT-PCR) Analysis of miRNAs}

Total RNA was extracted from the cell pallet using TRIzol ${ }^{\circledR}$ reagent (Invitrogen, Carlsbad, CA, USA) according to the manufacturer's protocol. qRT-PCR analysis was performed based on two-step qRT-PCR (30). Briefly, in the reverse transcription (RT) step, each RNA sample was reverse transcribed to cDNA using the TaqMan $^{\circledR}$ miRNA Reverse Transcription Kit (\#PN 4366597, Applied Biosystems, Foster City, CA, USA). Each reaction contained $10 \mathrm{ng}$ of RNA, $50 \mathrm{U}$ of Multiscribe Reverse Transcriptase, $100 \mathrm{mM}$ of deoxyribonucleotide triphosphate, $1 \times$ reaction buffer, $4 \mathrm{U}$ of RNase inhibitor, and $1 \times$ specific miRNA primers (TaqMan MicroRNA Assay, PN 4427975, Applied Biosystems) with nuclease-free $\mathrm{H}_{2} \mathrm{O}$ to $15 \mu \mathrm{l}$ of final volume. The reaction mixture was then incubated at $16^{\circ} \mathrm{C}$ for $30 \mathrm{~min}$, followed by incubation at $42^{\circ} \mathrm{C}$ for $30 \mathrm{~min}$. The enzyme was then inactivated at $85^{\circ} \mathrm{C}$ for $5 \mathrm{~min}$. In the TaqMan real-time PCR step, $2 \mu \mathrm{l}$ of cDNA solution was amplified using $1 \times$ specific miRNA primers (TaqMan MicroRNA Assay), 1× TaqMan Universal Master Mix II (\#PN 44440040, Applied Biosystems, Darmstadt, Germany), and nuclease-free $\mathrm{H}_{2} \mathrm{O}$ to $10 \mu \mathrm{l}$ of final volume. Quantitative PCR was performed on a 7500 System quantitative PCR machine (Applied Biosystems, Darmstadt, Germany) using a two-step PCR protocol with a denaturation step at $95^{\circ} \mathrm{C}$ for $10 \mathrm{~min}$, followed by 40 cycles with a denaturation step at $95^{\circ} \mathrm{C}$ for $15 \mathrm{~s}$, and an annealing/ elongation step at $60^{\circ} \mathrm{C}$ for $60 \mathrm{~s}$. The cycle threshold $(\mathrm{Ct})$ values were calculated using the SDS 2.1 software (Applied Biosystems, Darmstadt, Germany). The relative amount of miRNA to small nuclear U6 snRNA (the internal control) was calculated using the equation $2^{-\Delta \mathrm{CT}}$, where $\Delta \mathrm{Ct}=(\mathrm{Ct}$ microRNA-Ct U6RNA $)$ data 
were analyzed as previously described (31). The target miRNA primer sequences were as follows: hsa-let-7b-5p (002619): 5' UGA GGU AGU AGG UUG UGU GGU U-3'; hsa-miR-29a-3p (002112): 5'-UAG CAC CAU CUG AAA UCG GUU A-3'; hsamiR-29b-3p (000413): 5'-UAG CAC CAU UUG AAA UCA GUG UU-3'; hsa-miR-130a-3p (000454), 5'-CAG UGC AAU GUU AAA AGG GCA U-3'. hsa-U6 snRNA (001973).

\section{Transfection of let-7b-5p Mimic and Inhibitor with Functional Validation}

A total of $2.5 \times 10^{5}$ cells $/ 0.5 \mathrm{ml}$ primary human $\mathrm{CD} 14^{+}$monocytes were maintained in RPMI-1640 medium supplemented with $10 \%$ FBS, $100 \mathrm{U} / \mathrm{ml}$ penicillin, $100 \mu \mathrm{g} / \mathrm{ml}$ streptomycin, and $0.25 \mu \mathrm{g} /$ $\mathrm{ml}$ Amphotericin $\mathrm{B}$ (GIBCO) at $37^{\circ} \mathrm{C}$ in a humidified incubator containing $5 \% \mathrm{CO}_{2}$. For functional analysis, Has-let-7b-5p mimics

\section{PMN}
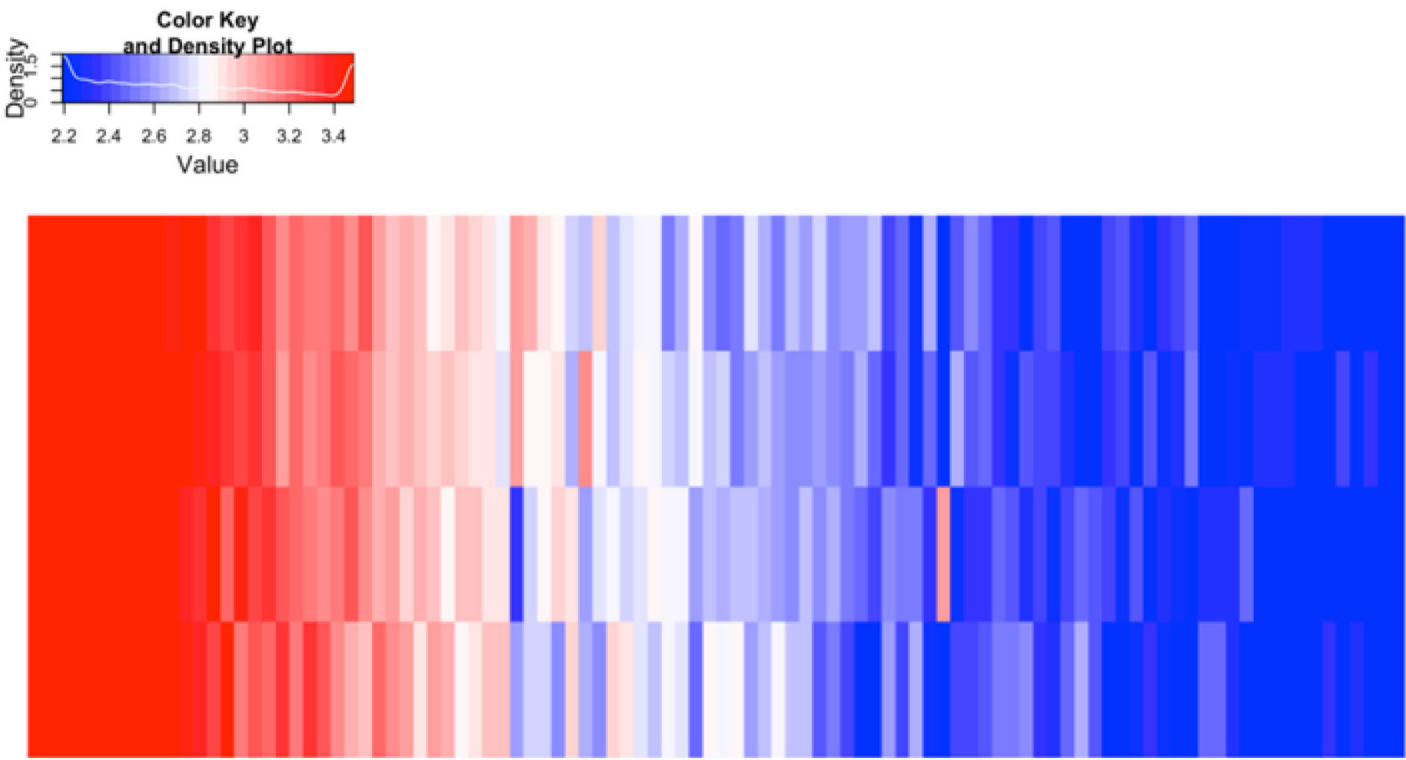

PMN.AD.C

PMN.AD.T

PMN.CB.C

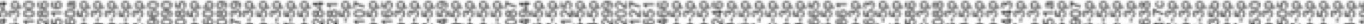

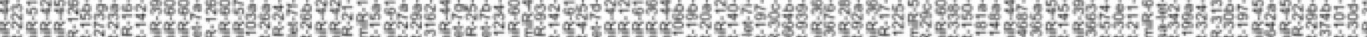

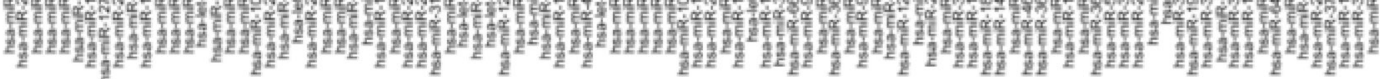

PMN.CB.T
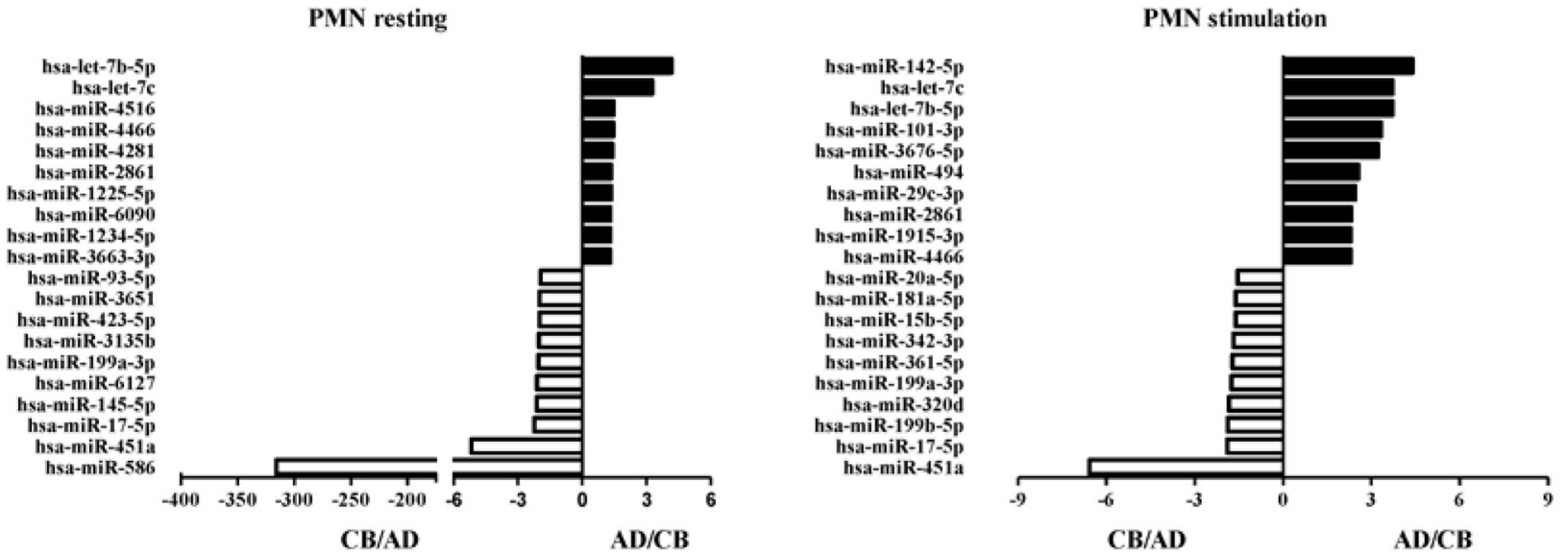

FIGURE 3 | Differential microRNA (miRNA) profiles between adult and neonatal polymorphonuclear cells (PMNs). Upper heat map showing distinct miRNA expression in activated and resting leukocyte subsets of adult peripheral blood and cord blood. Each heat map lane represents the top 100 expressed miRNAs in each leukocyte subset. Higher intensity is shown in red and lower intensity in blue. Lower bar charts showing the top 10 differentially expressed miRNAs in adult (black bar) or (white bar) neonate cells in specific leukocytes at resting (left) or activated states (right). The expression of miRNAs is represented as relative folds. Has, Homo sapiens. 
(\#47-775, EXIQON, TGAGGTAGTAGGTTGTGTGGTT), Haslet-7b-5p miRCURY LNA ${ }^{\mathrm{TM}}$ microRNA inhibitor (\#4100945, EXIQON, ACCACACAACCTACTACCTC), cel-miR-39-3p miRCURY LNA ${ }^{\mathrm{TM}}$ microRNA Mimic Negative Control (\#479902, EXIQON, TCACCGGGTGTAAATCAGCTTG), and miRCURY LNA ${ }^{\mathrm{TM}}$ microRNA inhibitor scramble control (\#199900, EXIQON, ACGTCTATACGCCCA) were used. The miR mimics and LNA inhibitors were transfected into CD14 ${ }^{+}$ cells using TransIT-X2 (Mirus, Madison, WI, USA) according to the manufacturer's instructions. Briefly, cells were plated in a 48-well plate. miR mimics $(50 \mu \mathrm{l})$ or LNA inhibitors and $1.5 \mu \mathrm{l}$ of TransIT-X2 Transfection Reagent were added separately to $450 \mu \mathrm{l}$ of RPMI-1640 medium (Invitrogen). The solution was then mixed to form the transfection complex. The transfection complex was added to cells with a final working concentration 20 or $40 \mathrm{nM}$ and incubated at $37^{\circ} \mathrm{C}$ for 24 or $48 \mathrm{~h}$, as indicated. After incubation with the transfection complex, the transfected cells were stimulated with or without LPS $(100 \mathrm{ng} / \mathrm{ml})$ for $16 \mathrm{~h}$. The culture supernatants were then collected for quantification of IL-6, IL-8, and TNF- $\alpha$ production by ELISA (R\&D Systems, Minneapolis, MN, USA, catalog number DY260,208 and DY210).

\section{Statistics}

Data are expressed as the mean \pm SEM. The Mann-Whitney $U$ test was used when two groups were analyzed. Results with a $p$-value of less than 0.05 were considered to be statistically significant. All

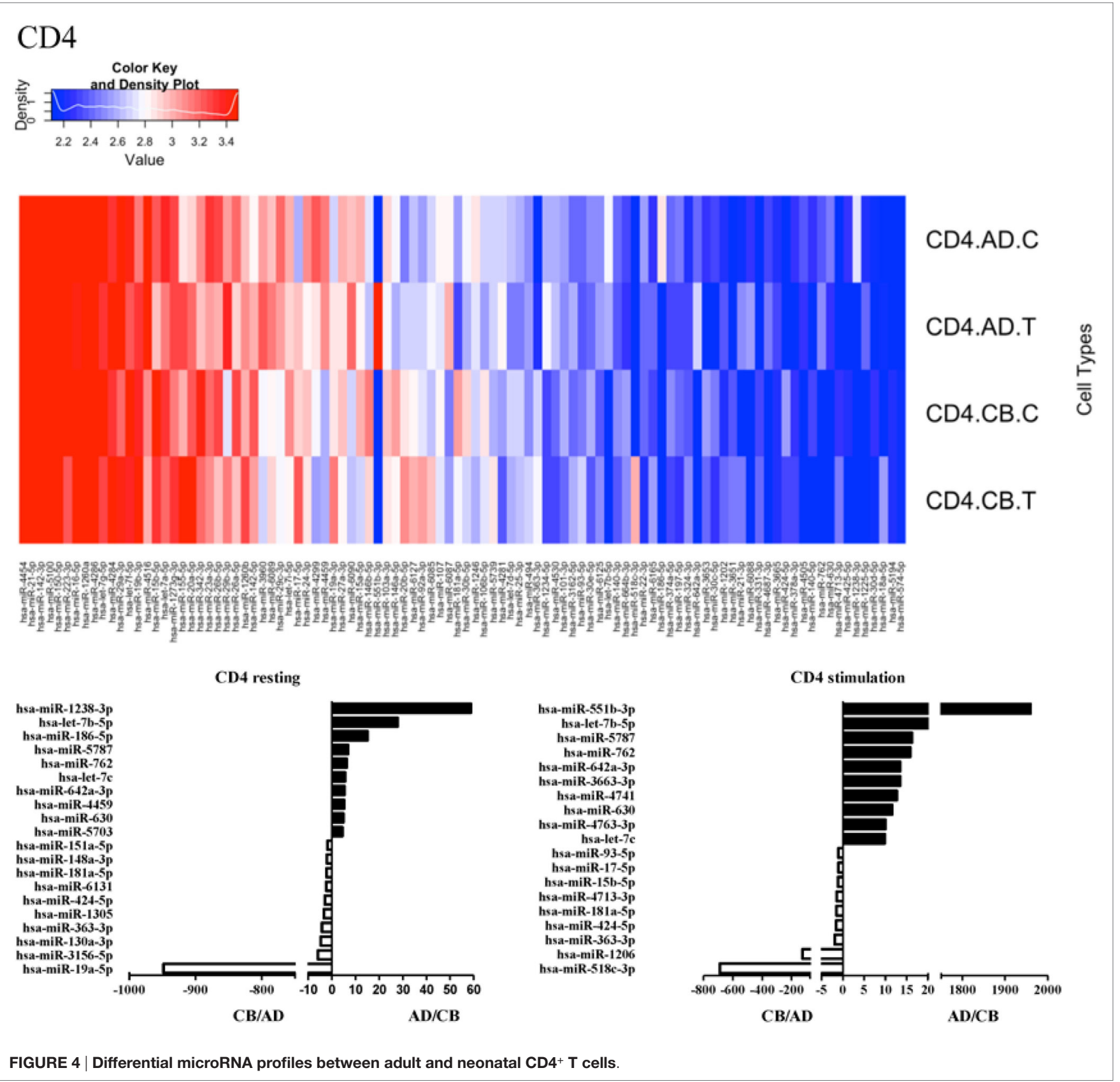




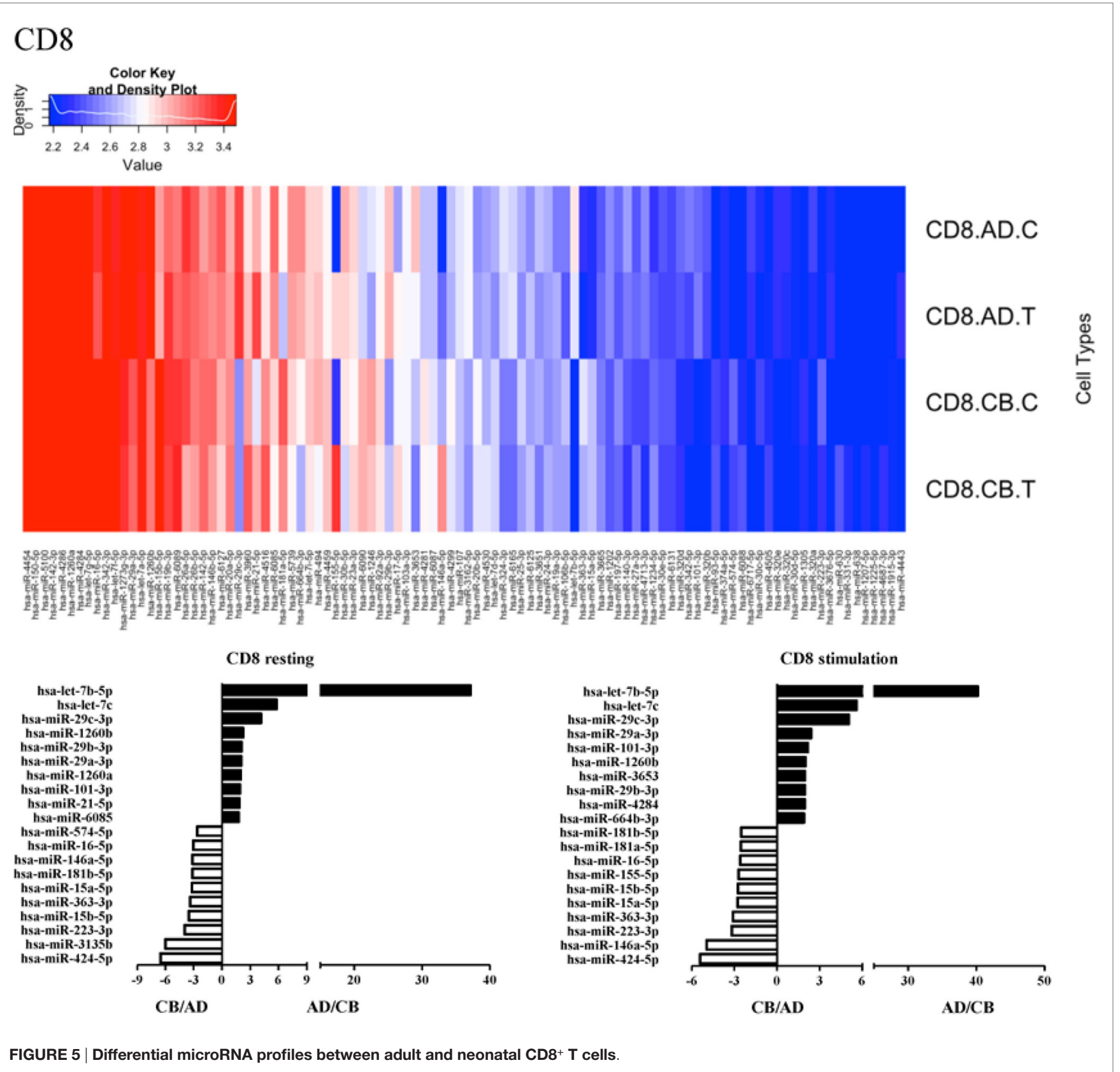

statistical tests were performed using the SPSS 19.0 for Windows XP (SPSS, Inc., Chicago, IL, USA).

\section{RESULTS}

\section{Hierarchical Clustering of Adult Peripheral Blood and Cord Blood Leukocyte Subpopulations Based on miRNA Expression}

According to the manufacturer's design, probe sets displaying a $\log 2$ signal value greater than 6 were linear and therefore reliable for miRNA analysis. Using data from the pooled samples, specific probe sets displayed an average $\log 2$ signal value greater than 6 in at least one cell type and were deemed to be expressed above background. PMNs, CD4 ${ }^{+} \mathrm{T}$ cells, $\mathrm{CD} 8^{+} \mathrm{T}$ cells, $\mathrm{CD} 14^{+}$ monocytes, and $\mathrm{CD}_{5} 6^{+} \mathrm{NK}$ cells were isolated from healthy adult peripheral or $\mathrm{CB}$ obtained from pools of five donors each. The $\mathrm{BDCA}^{+}$mDCs were obtained from pools of 10 healthy adult peripheral or $\mathrm{CB}$ donors. The $\mathrm{BDCA} 4^{+} \mathrm{pDCs}$ were obtained from pools of 19 healthy adult peripheral blood and $31 \mathrm{CB}$ donors for its little amount. Subjects were randomized across pools for gender. We chose to pool samples in order to get sufficient cell numbers for rare cell types and to decrease sample variation. Because of the rare amount of dendritic cells, normalized miRNA expression data from one chip array with 


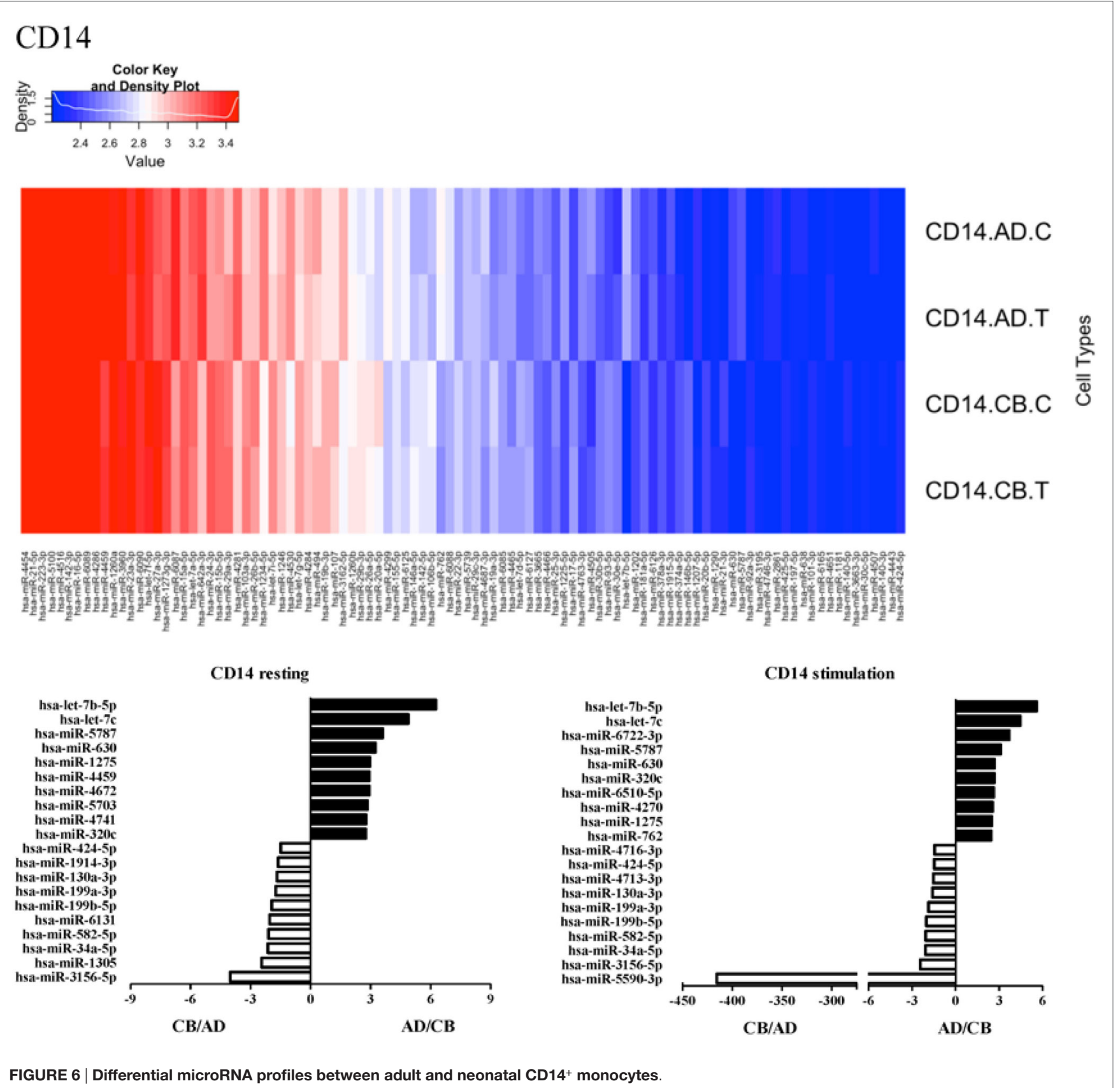

pooled leukocytes were analyzed in this study. The array data have been submitted to GEO and assigned an accession number "GSE89853." The raw data are now available and open for the researcher community. Full lists of normalized miRNA expression are shown in Table S1 in Supplementary Material. An unsupervised hierarchical cluster analysis of the top 100 most abundant miRNAs revealed discrete miRNA profiles for adult and CB leukocyte subsets, including unique miRNA signatures for each cell lineage (Figure 1A).

In order to characterize the specific miRNA expression between myeloid and lymphoid leukocytes, adult leukocyte subsets were divided into myeloid (PMNs, monocytes, and mDCs) and lymphoid groups (CD4 ${ }^{+}, \mathrm{CD} 8^{+} \mathrm{T}$ cells, and $\mathrm{CD} 19^{+} \mathrm{B}$-cells). The miRNA profiles of these two groups were compared as shown in Figure 1B. Samples from the same origin (myeloid or lymphoid) had similar miRNA expression profiles and were clustered together. Myeloid and lymphoid leukocytes have unique miRNA profiles that demonstrate the difference in their development. miR-744-5p, miR-4763-3p, miR-1207-5p, miR-3656, and miR6090 were predominantly expressed in myeloid cells. In contrast, let-7g-5p (especially in CD4 ${ }^{+} \mathrm{T}$ cells), miR-342-3p, miR-324-3p, miR-3607-3p, miR-215 (especially in CD8 ${ }^{+} \mathrm{T}$ cells), let-7a-5p, miR-95, miR-151a-3p, miR-222-3p, miR-3127-5p, miR-4284, and miR-3609 (especially in B-cells) were expressed mainly in 


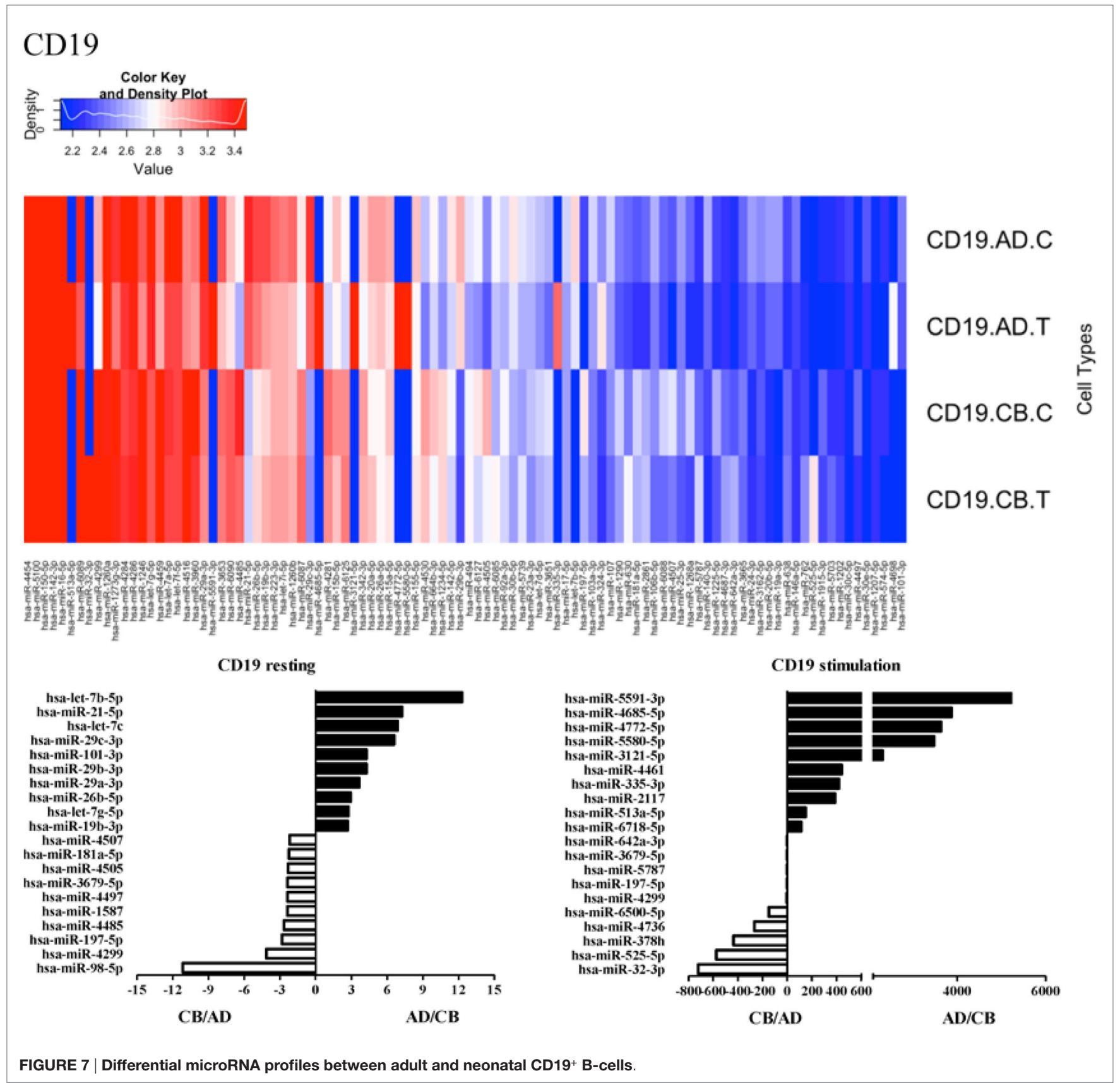

lymphoid cells. Interestingly, two members of the let-7 family (let-7a-5p and let-7g-5p) were present in the set of abundantly expressed miRNAs in lymphoid cells.

\section{miRNA Signature Distinguished Adult and Neonatal Leukocyte Subsets}

A lower filter threshold ( $\log 2$ signal value greater than 6) was initially set for miRNA analysis. Adult CD $14^{+}$monocytes demonstrated higher miRNA expression (269 miRNAs) than other leukocyte subsets, while adult pDCs had the lowest miRNA expression (98 miRNAs) (Table S2 in Supplementary Material).
When comparing adult and CB leukocyte subsets, the Venn diagrams also showed common and unique miRNA transcripts in indicated leukocytes before and after stimulation (Figure 2). There were significant overlaps between adult and neonatal leukocyte subsets. We also applied a higher filter ( $\log 2$ signal value greater than 10) to identify the highly expressed miRNA transcripts among the different leukocyte subsets. With the higher filter, adult $\mathrm{CD} 14^{+}$monocytes had the highest number of miRNAs (66 miRNAs) compared to other leukocyte subsets, while adult pDCs had the lowest number of miRNAs (13 miRNAs) (Table S2 in Supplementary Material). Figure 2B demonstrates the common and unique miRNA transcripts in indicated leukocytes 


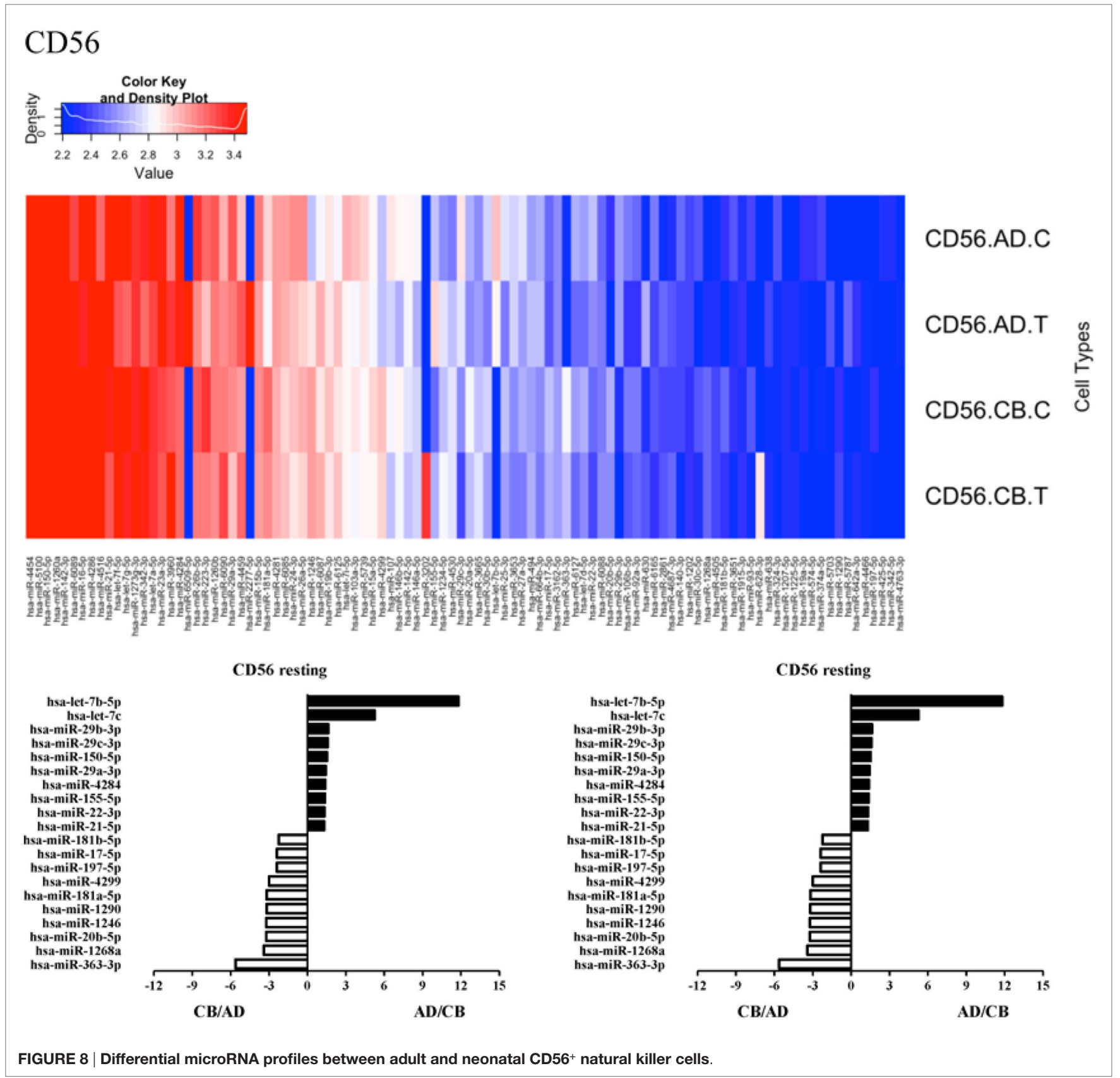

subsets between adult and CB with the higher filter. Significant overlaps between the adult and neonatal leukocyte subsets were also observed with the higher filter range. Using a higher filter, mDCs had the least overlap of miRNAs between adult and neonatal leukocytes $(5 / 26 ; 19.2 \%$ overlap). These common and unique miRNA transcripts detail between indicated adult and CB leukocyte subsets in Table S3 in Supplementary Material.

\section{Leukocytes miRNA Signature Altered after Stimulation}

Since the major roles of immune cells are to defend the body against foreign substances, stimulation is needed to activate immune responses. Therefore, we also compared the miRNA profiles of leukocyte subsets between adult and neonate samples upon stimulation. Among the differentially expressed miRNA, the top 20 miRNAs expressed in specific leukocytes from adult (more than or less than neonate) samples were chosen and illustrated. The differentially expressed miRNA profiles of PMNs, $\mathrm{CD}^{+} \mathrm{T}$ cells, $\mathrm{CD}^{+} \mathrm{T}$ cells, CD $14^{+}$monocytes, CD $19^{+} \mathrm{B}$-cells, $\mathrm{CD}^{2} 6^{+} \mathrm{NK}$ cells, mDCs, and pDCs are shown in Figures 3-10, respectively. Under resting conditions, compared to adult counterparts, the top 10 underexpressed miRNAs in CB PMNs were let-7b-5p, let-7c, miR-4516, miR-4466, miR-4281, miR-2861, miR-1225-5p, miR-6090, miR-1234-5p, and miR-3663-3p. The 


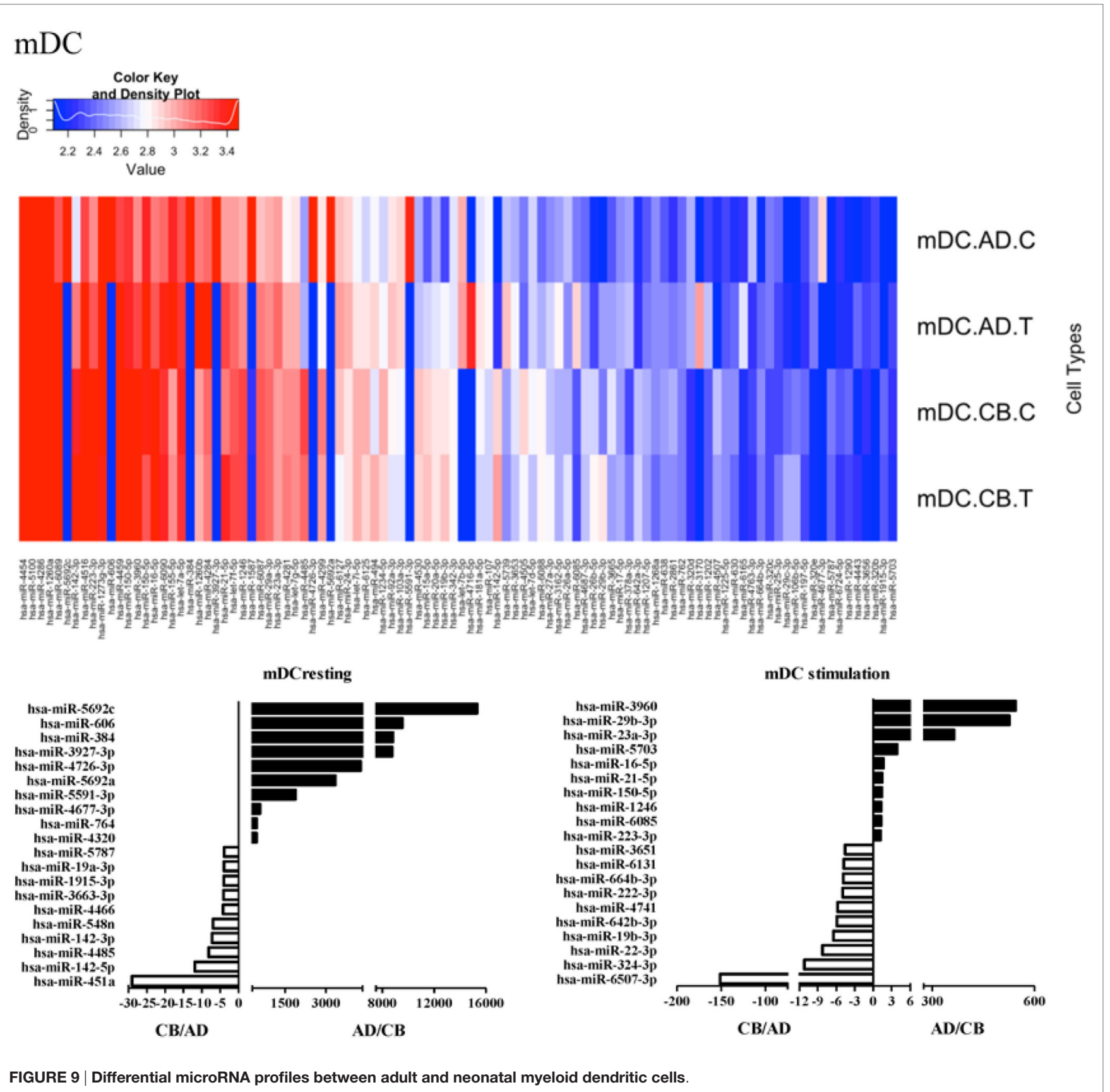

top 10 miRNAs (miR-586, miR-451a, miR-17-5p, miR-145-5p, miR-6127, miR-199a-3p, miR-3135b, miR-423-5p, miR-3651, and miR-93-5p) were overexpressed in CB PMNs (Figure 3). Upon LPS stimulation, compared to adult counterparts, the top 10 underexpressed miRNAs in CB PMNs were miR-142-5p, let7c, let-7b-5p, miR-101-3p, miR-3676-5p, miR-494, miR-29c-3p, miR-2861, miR-1915-3p, and miR-4466, while the top 10 miRNAs overexpressed in CB PMNs were miR-451a, miR-17-5p, miR199b-5p, miR-320d, miR-199a-3p, miR-361-5p, miR-342-3b, miR-15b-5p, miR-181a-5p, and miR-20a-5p (Figure 3). With LPS stimulation, miR-142-5p exhibited the highest expression in adult PMNs compared to CB PMNs and miR-451a showed the highest expression in neonatal PMNs compared to adult PMNs. let-7b-5p and miR-142-5p exhibited the highest expression in adult PMNs compared to neonatal PMNs at resting and activated states, respectively. miR-586 and miR-451a exhibited the highest expression in cord PMNs compared to adult PMNs at resting and activated states, respectively. These dynamic changes in miRNA profiles correspond to the functional roles of miRNAs in immune cells during stimulation. Similarly, miR-1238-3p exhibited the highest expression in adult $\mathrm{CD}^{+} \mathrm{T}$ cells compared to neonatal $\mathrm{CD}^{+} \mathrm{T}$ cells at resting state (Figure 4). miR-19a-5p 

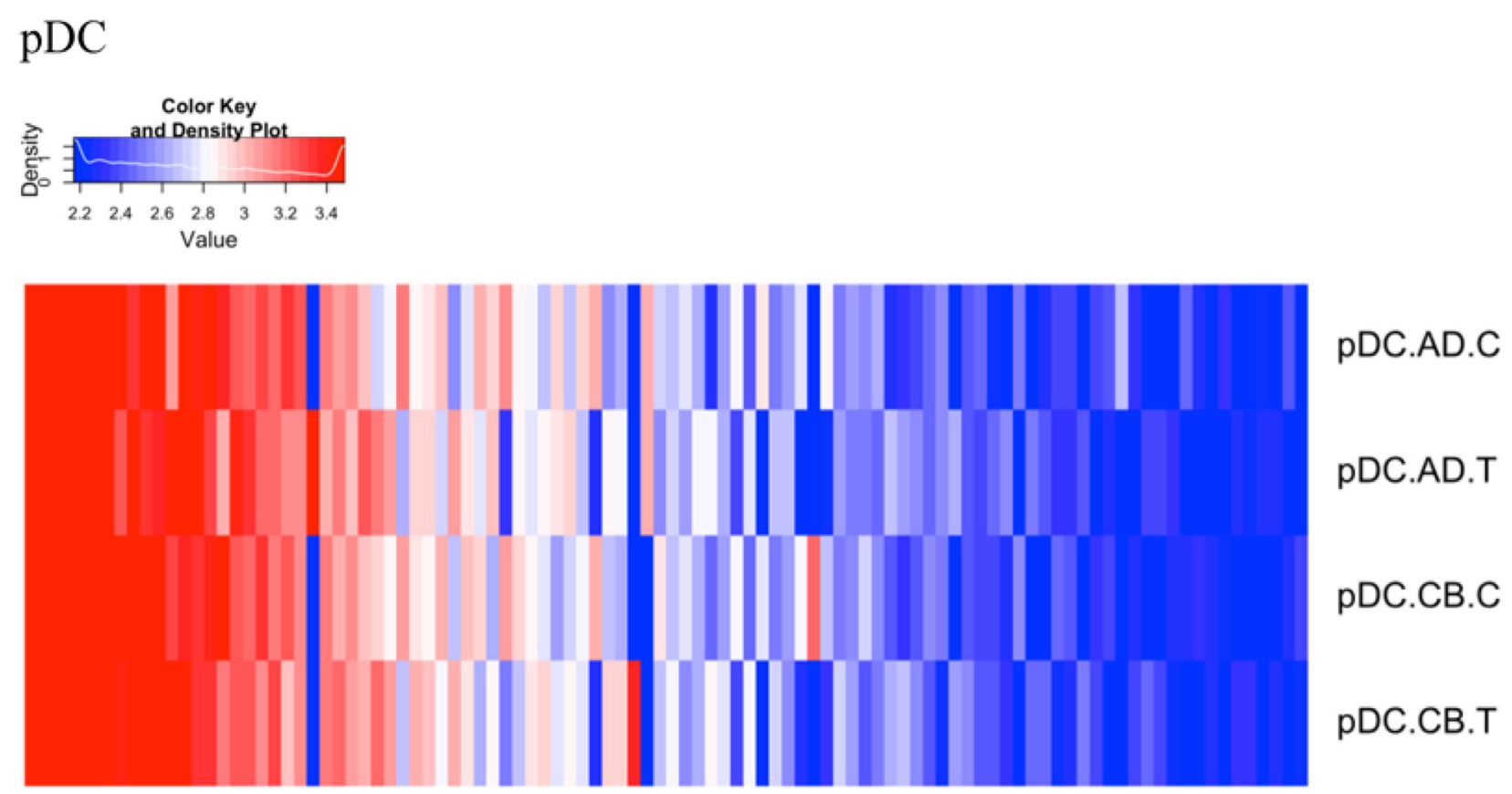

$\begin{array}{ll}\text { pDC.AD.T } & \stackrel{\wp}{\$} \\ \text { pDC.CB.C } & \overline{\bar{\Phi}}\end{array}$

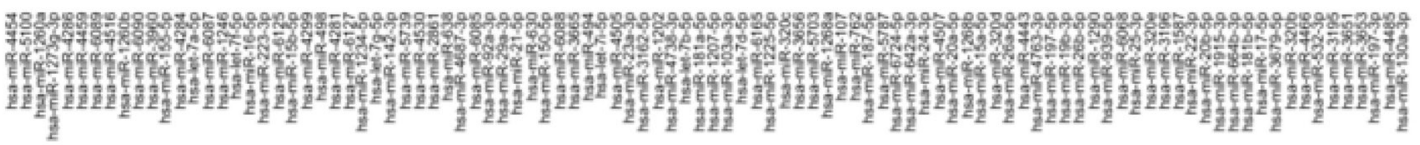

pDC.CB.T
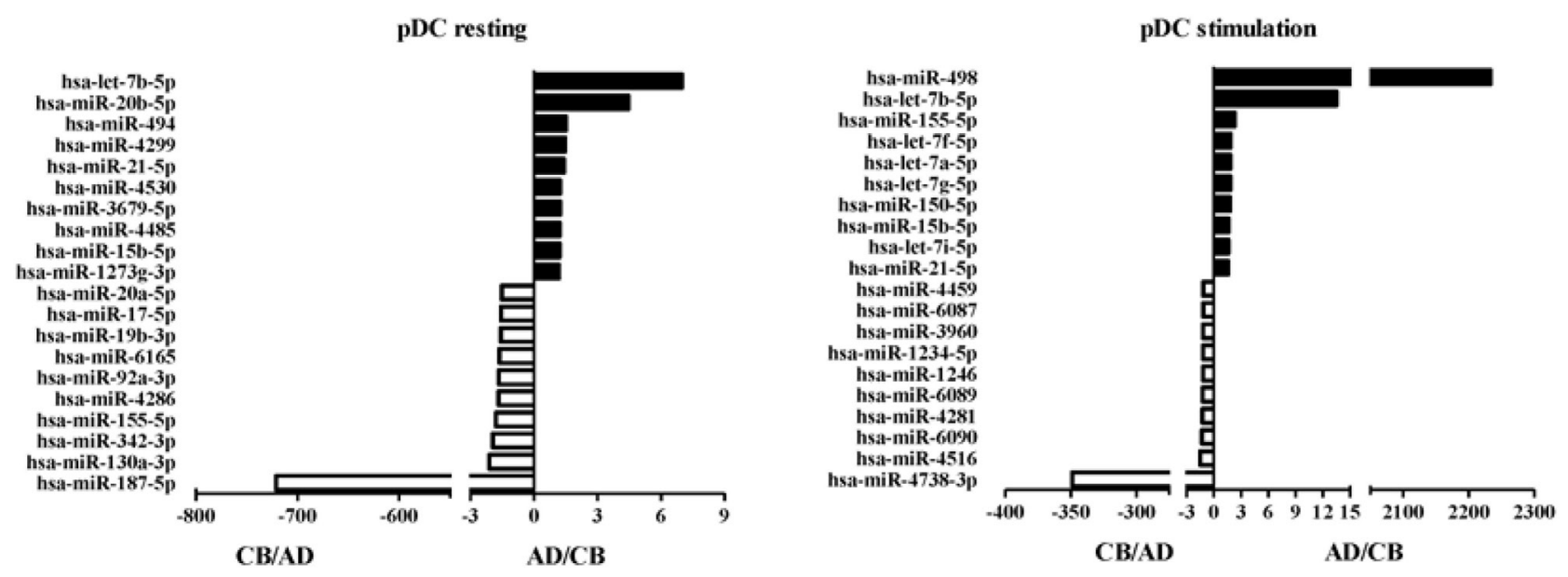

FIGURE 10 | Differential microRNA profiles between adult and neonatal plasmacytoid dendritic cells.

had the highest expression in neonatal $\mathrm{CD} 4^{+} \mathrm{T}$ cells compared to adult $\mathrm{CD}^{+}$T-cells at resting state. With PHA stimulation, miR-551b-3p exhibited the highest increase in expression in adult $\mathrm{CD}^{+} \mathrm{T}$ cells. miR-518c-3p showed the highest expression in neonatal $\mathrm{CD}^{+} \mathrm{T}$ cells compared to adult $\mathrm{CD} 4^{+} \mathrm{T}$ cells after PHA stimulation. Interestingly, let-7b-5p exhibited higher expression in adult monocytes compared to neonatal monocytes with or without stimulation (Figure 6). Likewise, we identified unique miRNA profiles of other leukocyte subsets between adults and neonates with or without stimulation. These unique miRNA profiles between adult and neonate leukocytes likely contribute to the altered immune function of neonates. It is noteworthy that adult peripheral leukocytes consistently demonstrated higher let$7 \mathrm{~b}-5 \mathrm{p}$ and lower miR-181a-5p expression than CB cells across multiple subsets, with or without stimulation.

Since the differentially expressed miRNAs were selected based on signal intensity from a chip array with pooled leukocytes, we selected let-7b-5p, miR-29a-3p, miR-29b-3p, and miR-130a-3p to validate the array results by $\mathrm{qRT}-\mathrm{PCR}$ in PMN, CD4 ${ }^{+} \mathrm{T}$ cells, and $\mathrm{CD}_{14}{ }^{+}$monocytes. As shown in Figure 11, the qRT-PCR 
PMN

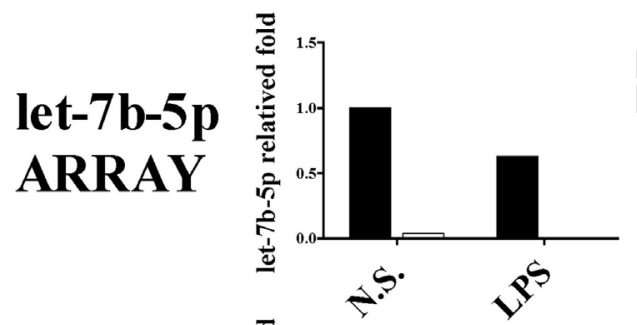

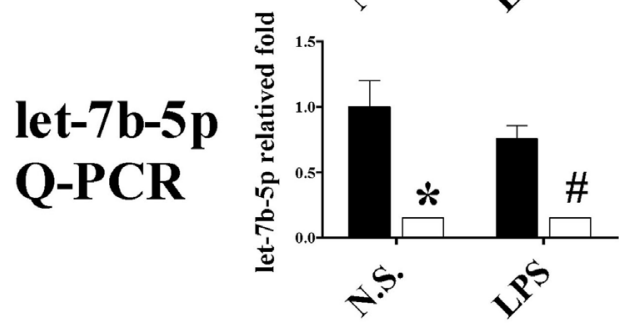
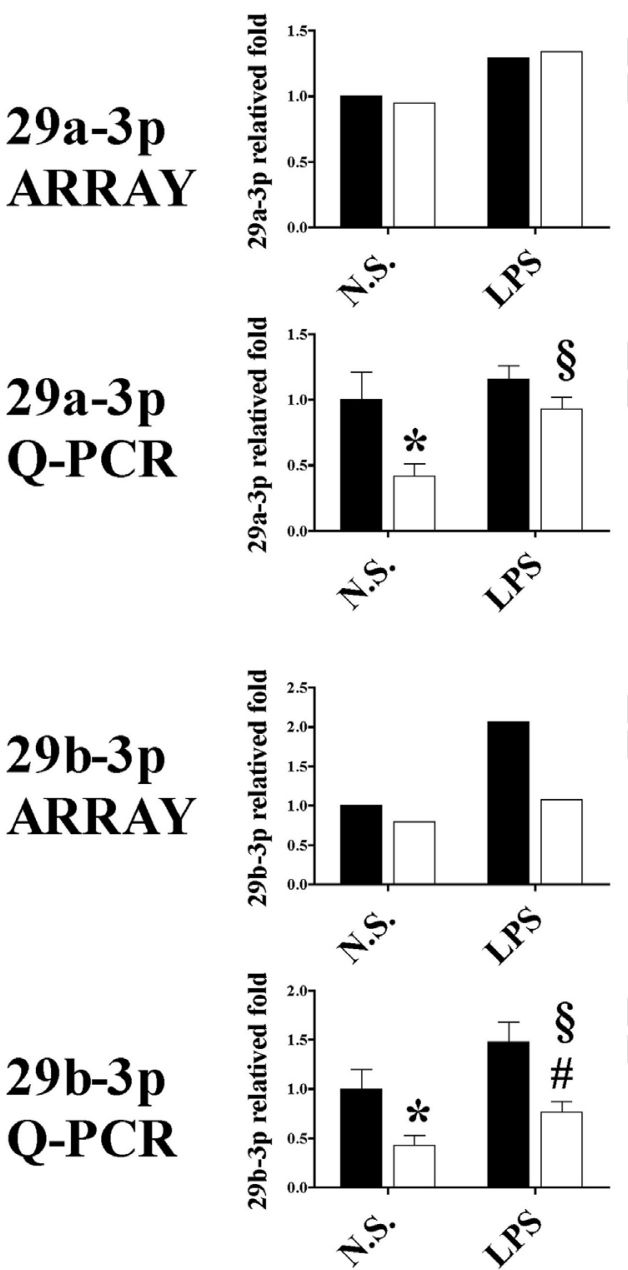

CD4
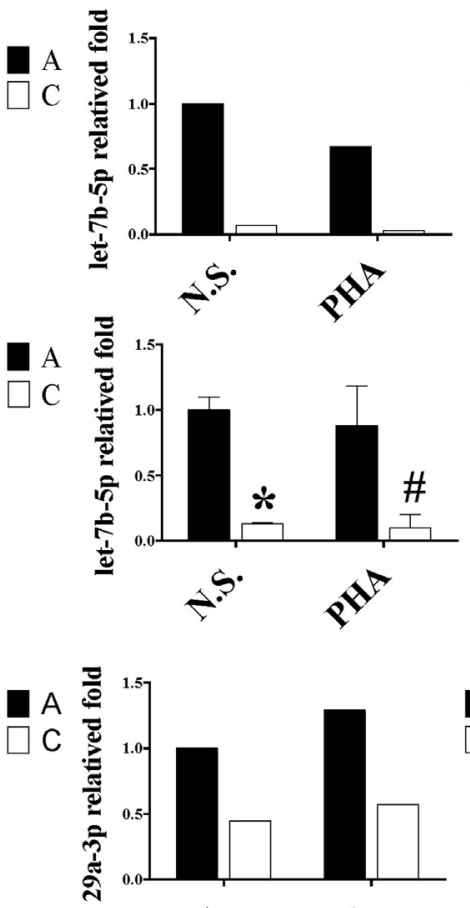

s.
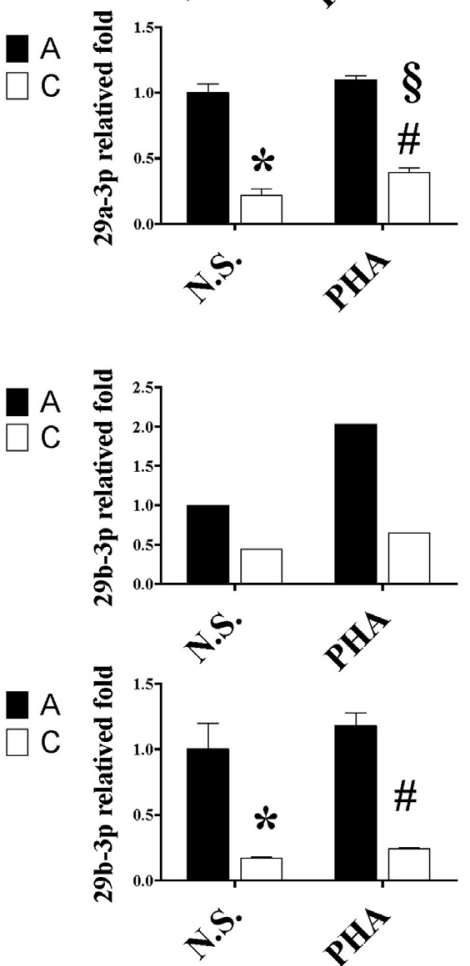

CD14
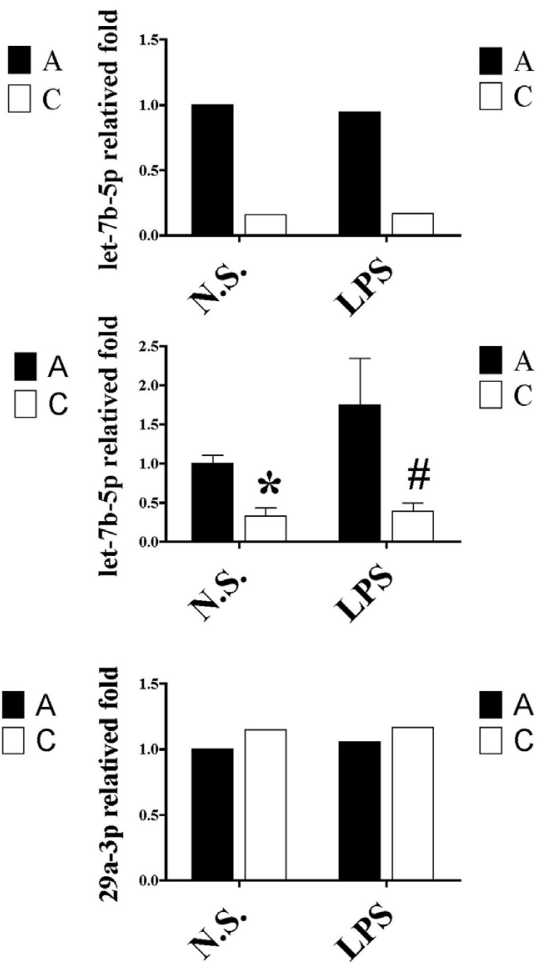

$\square \mathrm{C}$
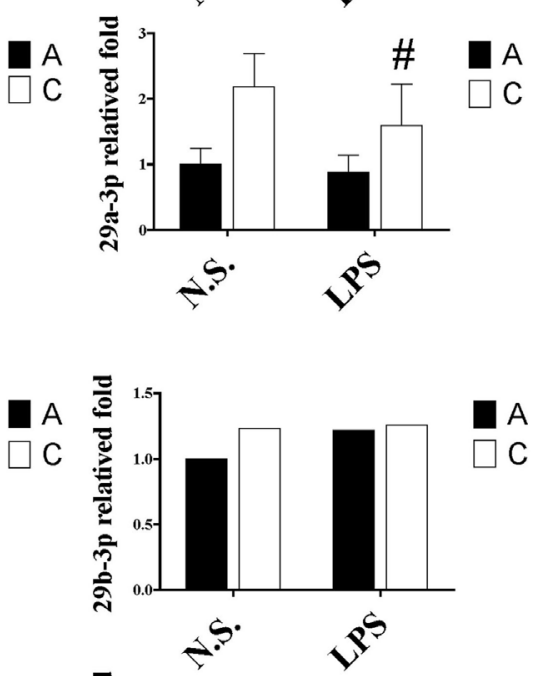

a

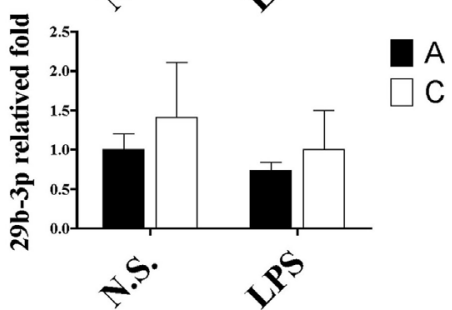

FIGURE 11 | Quantitative reverse transcription PCR (qRT-PCR) validation of let-7b-5p, 29a-3p, 29b-3p, and miR-130a-3p expression in various leukocyte subsets from cord blood (CB) and adult peripheral blood. 


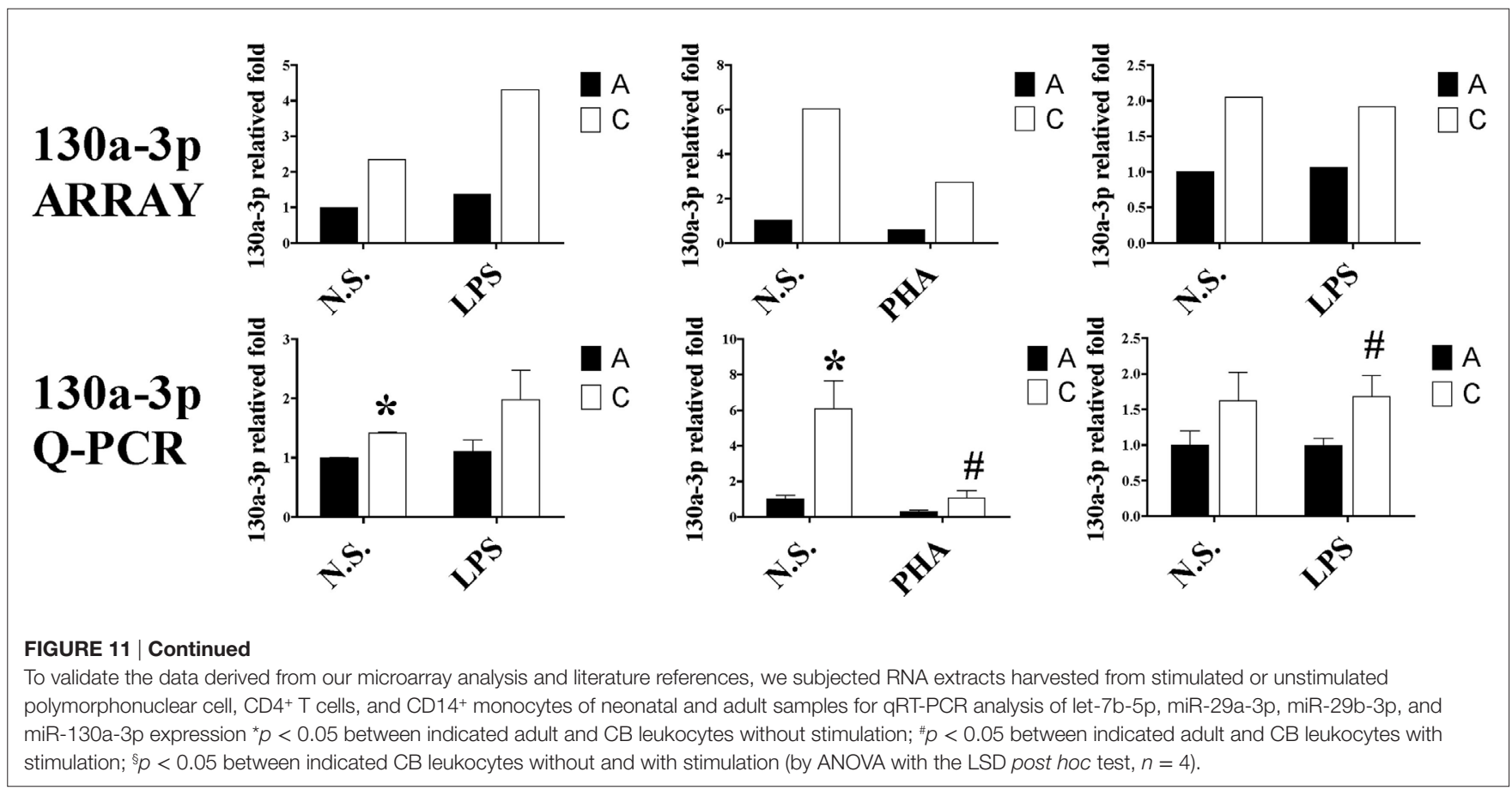

results demonstrated a decrease in the expression of miR-29a-3p in PMNs and $\mathrm{CD}^{+} \mathrm{T}$ cells of $\mathrm{CB}$ compared to adult cells, as opposed to $\mathrm{CD} 14^{+}$monocytes. A similar trend to miR-29a-3p was observed with the expression of miR-29b-3p, whereas the expression of miR-130a-3p was higher in neonatal PMN, CD4 ${ }^{+}$ $\mathrm{T}$ cells, and $\mathrm{CD} 14^{+}$cells. These data were consistent with the microarray results.

\section{Functional Validation of let-7b-5p on Pro-inflammatory Cytokine Production by Monocytes}

In the next study, monocytes were selected for further functional validation of let-7b-5p. Because adult monocytes had higher let-7b-5p expression than CB, we transfected a let-7b-5p inhibitor and let-7b-5p mimic into adult monocytes and $\mathrm{CB}$ monocytes, respectively. The transfection efficiency of the let-7b-5p inhibitor and mimic were determined by qPCR. As shown in Figure S1 in Supplementary Material, transfection of the let-7b-5p inhibitor into adult monocytes for $24 \mathrm{~h}$ suppressed let-7b expression 0.05 -fold (at 20 and $40 \mathrm{nM}$ of let$7 b-5 p$ inhibitor), white transfection of the let-7b-5p mimic into CB monocytes enhanced the expression of let-7b-5p 16,000- (at $20 \mathrm{nM}$ of let-7b-5p mimic) and 20,000-fold (at $40 \mathrm{nM}$ let-7b-5p mimic).

The function of let-7b-5p on the pro-inflammatory cytokine production was determined. Upon LPS stimulation, the monocytes produced large amounts of IL-6, IL-8, and TNF- $\alpha$. Cord blood monocytes showed higher IL-6 (12,265 \pm 1,387 vs. $4,623 \pm 1,474 \mathrm{pg} / \mathrm{ml})$ and TNF- $\alpha(2,436 \pm 706$ vs. $536 \pm 54 \mathrm{pg} /$ $\mathrm{ml}$ ) production than adult monocytes (Figure 12). Transfection of the let-7b-5p inhibitor ( $20 \mathrm{nM}$ ) into adult monocytes for $24 \mathrm{~h}$ enhanced IL-6 production (Figure 13A). Transfecting the let$7 \mathrm{~b}-5 \mathrm{p}$ mimic into $\mathrm{CB}$ monocytes for $24 \mathrm{~h}$ did not significantly suppress IL- 6 production, although there was a trend. After transfecting let-7b-5p mimic into CB monocytes for $48 \mathrm{~h}$, IL-6 production was suppressed with $40 \mathrm{nM}$ of let-7b-5p mimic (Figure 13B). Transfection of the let-7b-5p inhibitor at 20 and $40 \mathrm{nM}$ for $24 \mathrm{~h}$ enhanced TNF- $\alpha$ production by adult monocytes (Figure 14A). However, transfection of let-7b-5p mimic at $20 \mathrm{nM}$ for $48 \mathrm{~h}$ was needed to suppress TNF- $\alpha$ production by $\mathrm{CB}$ monocytes (Figure 14B). These results suggest that the modulatory effects of $\mathrm{CB}$ monocytes could be achieved with let- $7 \mathrm{~b}$ mimic, but a longer incubation time is needed. Either transfection with the let-7b-5p inhibitor or let-7b-5p mimic for 24 or $48 \mathrm{~h}$ had no influence on IL-8 production by adult or CB monocytes (Figures 15A,B).

\section{DISCUSSION}

Blood contains different leukocyte subsets owning distinct gene expression profiles corresponding to distinct immune functions upon stimulation. Since miRNA behavior at the molecular level is context and cell type dependent, knowing the distinct functions of specific mRNAs in adult and neonatal leukocyte subsets can help to clarify the mechanisms leading to altered immunity in newborns. In this study, we conducted a systematic and comprehensive analysis of functional miRNAs in purified PMN, monocytes, T cells, NK cells, B cells, pDCs, and mDCs from neonates and adults. Transfection of the let-7b inhibitor into adult monocytes significantly enhanced IL- 6 and TNF- $\alpha$ production, while transfection of a let-7b mimic into $\mathrm{CB}$ monocytes significantly suppressed the production of these cytokines. Accordingly, functional validation identified higher IL-6 and TNF- $\alpha$ production by CB monocytes than adult monocytes upon 
A IL-6

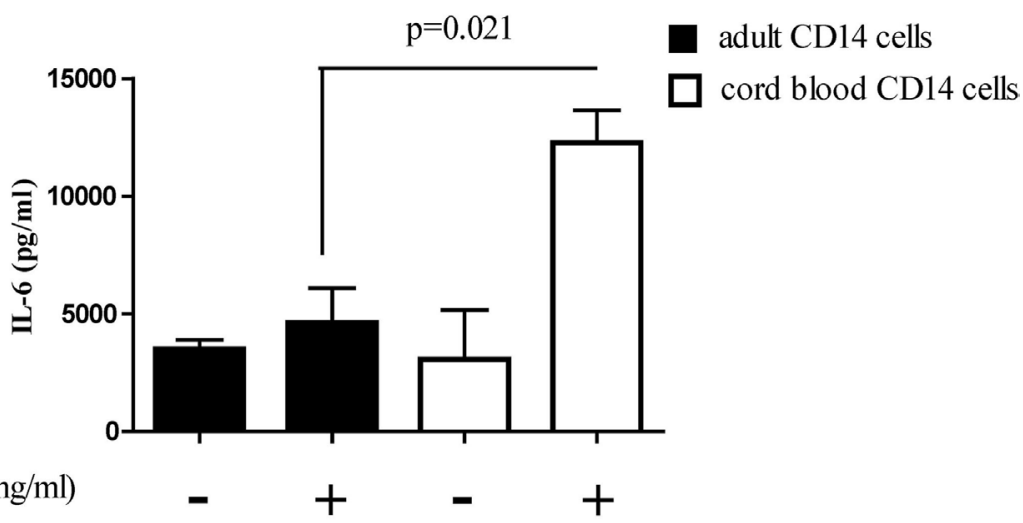

$\operatorname{LPS}(100 \mathrm{ng} / \mathrm{ml}) \quad$ - $\quad$ +

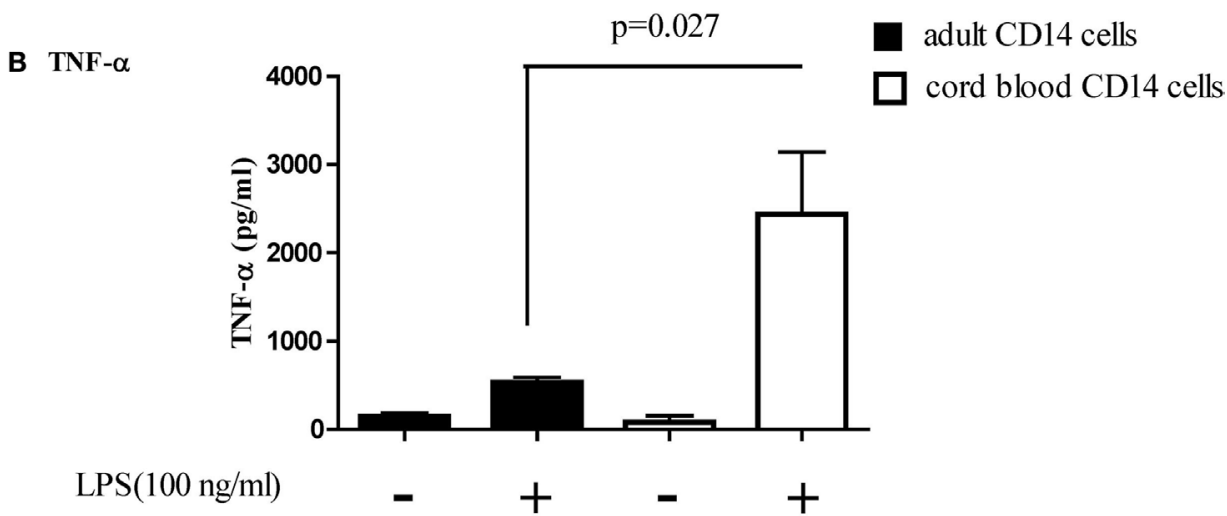

C $\mathrm{IL}-8$

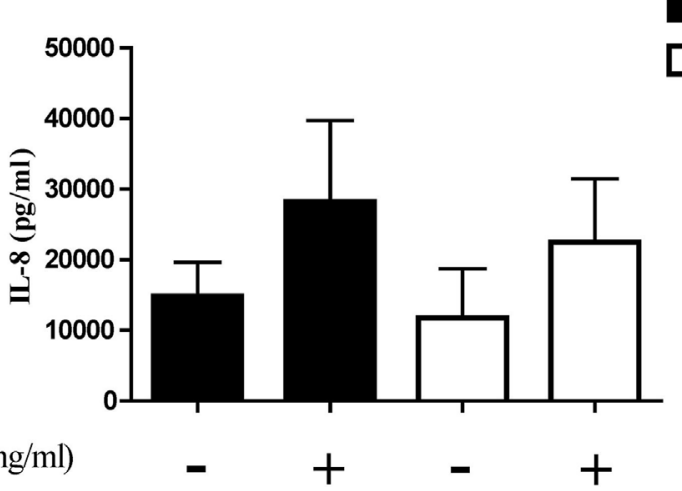

adult CD14 cells

cord blood CD14 cells

FIGURE 12 Adult and cord blood (CB) monocytes produced large amounts of pro-inflammatory cytokines upon LPS stimulation. Adult and CB monocytes were stimulated with LPS for 16 h, and then the supernatant was collected for quantification of (A) interleukin (IL)-6, (B) IL-8, and (C) TNF- $\alpha$ secretion. ${ }^{*} p<0.05$ between adult and CB monocytes with Mann-Whitney $U$ test $(n=5)$.

LPS stimulation. This is, at least partly, due to their lower let-7b expression. Our results demonstrate the essential roles of specific miRNAs in regulating neonatal immune functions and provide insight into the molecular mechanism.

Understanding of the immune response in disease is an important issue for living organisms. The immune system is a complex system of interacting cells whose primary purpose is to identify foreign substances. To exhibit proper immune function, the immune cells must undergo activation, proliferation, and cytokine production upon encountering antigens (27). Therefore, activated leukocyte subsets have more biological transcripts than resting cells $(3,23)$. In order to investigate the corresponding innate or adaptive immune response, leukocyte subsets were isolated and stimulated with LPS, PHA, or CpG ODN as indicated in this study. LPS is a component of Gram-negative bacteria and is used in in vitro studies to assess innate immune responses to Gram-negative bacterial infection $(32,33)$. PHA is a lectin that binds to the sugars on glycosylated surface proteins, including 
A

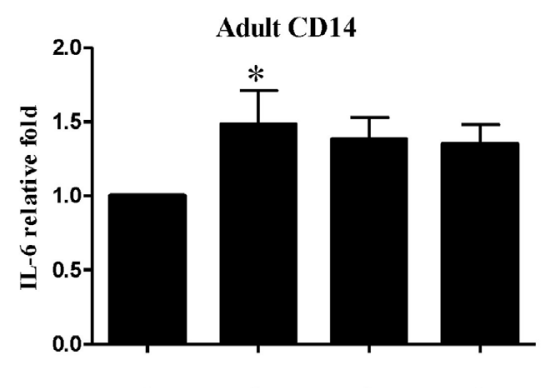

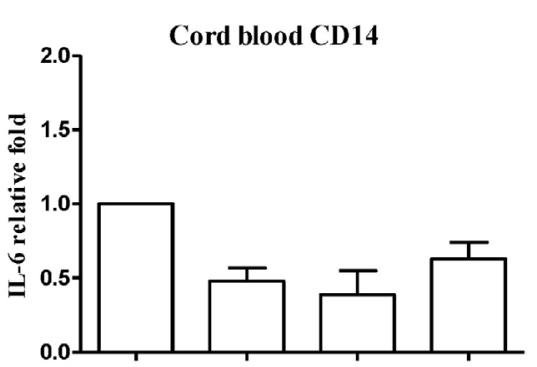

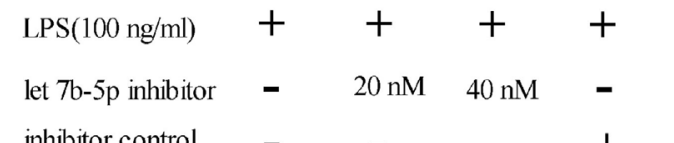

$\operatorname{LPS}(100 \mathrm{ng} / \mathrm{ml}) \quad+\quad+\quad+$

let 7b-5p mimic - $20 \mathrm{nM} \quad 40 \mathrm{nM} \quad$ -

mimic control $\quad-\quad$ - $\quad$ - $\quad+$

B

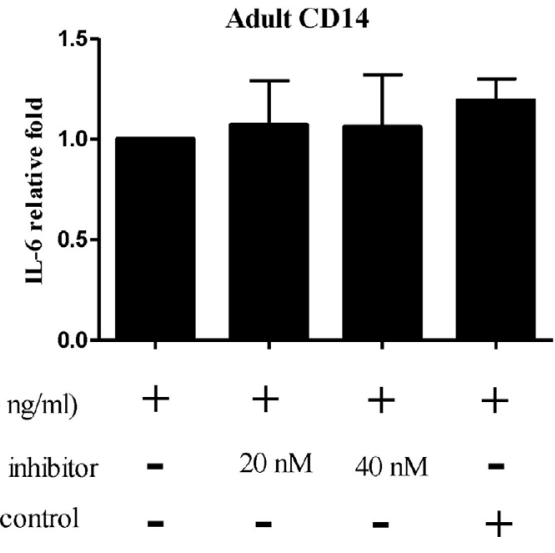

FIGURE 13 | The effect of let-7b-5p on interleukin (IL)-6 production by monocytes. let-7b-5p inhibitor transfected or untransfected adult monocytes and let-7b-5p mimic transfected and untransfected CB monocytes were subjected to detection of the IL- 6 protein after LPS stimulation for $16 \mathrm{~h}$. The transfection times were (A) $24 \mathrm{~h}$ and (B) $48 \mathrm{~h}$. IL-6 production is represented as relative fold expression compared to the LPS stimulation control. ${ }^{*} p<0.05$ as compared with LPS stimulation only with Mann-Whitney $U$ test $(n=5)$

the $\mathrm{T}$ cell receptor, and thereby crosslinks T cell activation signals. PHA has been widely used to stimulate human lymphocytes (34), whereas unmethylated CpG ODN is a ligand for TLR9 of pDCs (29). We chose LPS as a stimulus for PMN, monocytes, and mDCs. PHA was used to stimulate lymphocytes and NK cells, while CpG ODN was used to stimulate pDCs. With this approach, we provide functionally differential miRNA expression profiling of specific immune cell subsets between neonates and adults.

Although some studies have reported differences in miRNA expression between cord and adult blood immune cells, most focused on the miRNA profiles of a single resting leukocyte subpopulation $(20,22,35)$. Several studies have provided miRNA profiles for limited leukocyte subsets without comparing to adults, thus providing only limited array information $(28,36,37)$. Our study identified many previously reported miRNAs as well as unidentified miRNAs in all leukocyte subsets. We determined that all adult leukocyte subsets show higher let-7b-5p expression than the corresponding $\mathrm{CB}$ leukocytes, irrespective of their activation state. The let-7 miRNA family has been reported to consistently demonstrate increased abundance in adult erythroid cells (38).
To the best of our knowledge, this study is the first to demonstrate the abundance of let-7b-5p in all adult leukocyte subsets compared to neonates. Our data also demonstrate that neonatal $\mathrm{CD}^{+} \mathrm{T}$ cells have more abundant miR-181a expression than adult $\mathrm{CD}^{+} \mathrm{T}$ cells as previously reported by Palin et al. (35). Furthermore, our data show that all neonatal leukocyte subsets have more abundant miR-181a expression than relevant cells in adults, besides $\mathrm{CD} 4^{+} \mathrm{T}$ cells. Our findings also correlate with that of Charrier et al. showing that neonatal pDCs have more abundant TLR signal-related miR-155-5p (called miR-155 previously) expression than adult pDCs at the resting state (22). Moreover, we found that miR-155-5p expression in adult pDCs is upregulated and compatible with neonatal pDCs after CPG ODN stimulation. Our study confirms the overexpression of miR-15b, miR-181a, miR-363, and miR-424 in CB CD4 ${ }^{+}$and $\mathrm{CD}^{+} \mathrm{T}$ cells, as previously reported (37). However, we did not observe significant change in miR-155 expression after LPS stimulation in our array data, as reported by Takahashi et al. (37). The dynamic changes of miR-155 presented in our previous study could explain this inconsistency (23). Higher miR-184 expression in CB CD4 ${ }^{+}$ $\mathrm{T}$ cells that regulate the abundance of NFAT1 has been reported 
A

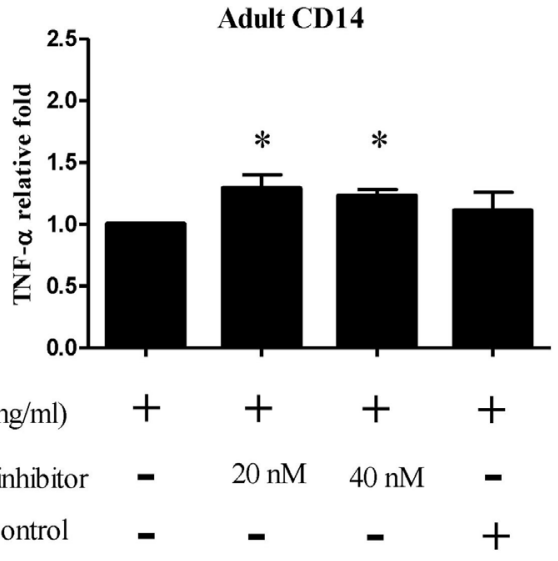

B

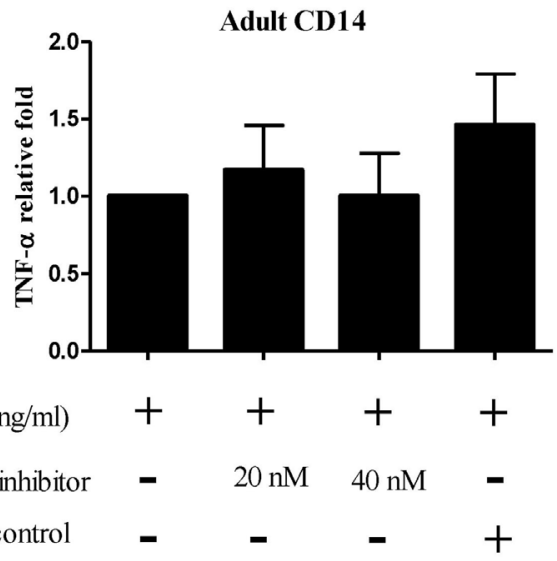

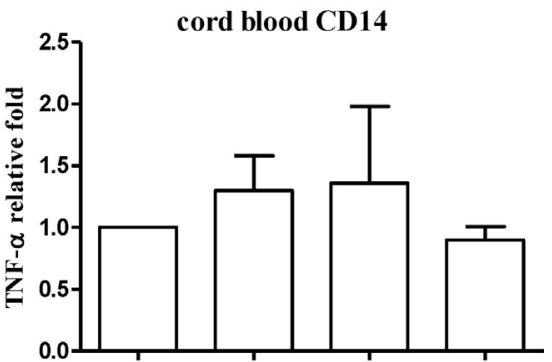

$\operatorname{LPS}(100 \mathrm{ng} / \mathrm{ml}) \quad+\quad+\quad+\quad+$

let $7 \mathrm{~b}-5 \mathrm{p}$ mimic - $20 \mathrm{nM} \quad 40 \mathrm{nM}$ -

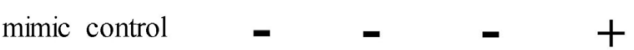

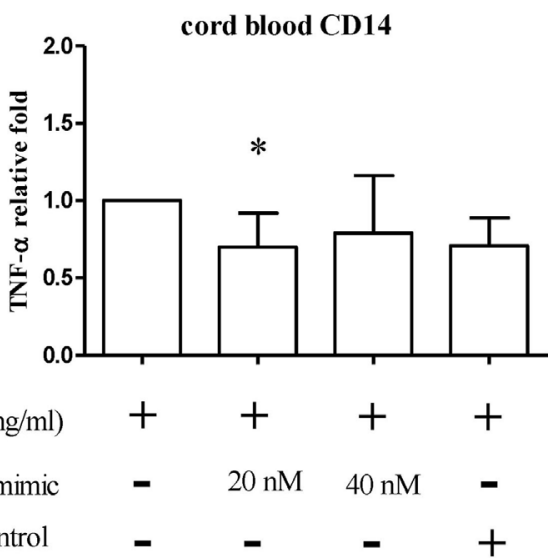

FIGURE 14 | The effect of let-7b-5p on TNF- $\alpha$ production by monocytes. Adult monocytes with or without let-7b-5p inhibitor transfection and cord blood monocytes with or without let-7b-5p mimic transfection were subjected to detection of TNF- $\alpha$ protein after LPS stimulation for 16 h. The transfection times were (A) $24 \mathrm{~h}$ and (B) $48 \mathrm{~h}$. TNF- $\alpha$ production is represented as relative fold expression compared to the LPS stimulation control. Data presented are calculated from five replicate measurements. ${ }^{*} p<0.05$ as compared with LPS stimulation only with Mann-Whitney $U$ test $(n=5)$.

(20). However, our data showed low miR-184 expression below the threshold setting, in adult and cord $\mathrm{CD} 4^{+} \mathrm{T}$ cells. Three small-RNA transcripts were expressed specifically in one cell type: miR-378 in monocytes, miR-31 in T cells, and miR-143 in neutrophils (25). In our study, we did observe specific miR-143 in neutrophils, although miR-378 and miR-31 were selectively expressed in adult and neonatal monocytes and T cells, respectively. These inconsistent results in miRNA expression among the different studies might be due to the differences of array or isolation kits used for study.

Based on our data, all adult leukocyte subsets illustrated higher let-7b-5p expression than the corresponding CB leukocytes. The higher let-7b-5p expression in adult leukocyte subsets was 3.7- to 63.0-fold that of neonates (Table S1 in Supplementary Material). PHA-stimulated adult $\mathrm{CD}^{+} \mathrm{T}$ cells and $\mathrm{CD}^{+} \mathrm{T}$ cells had higher let-7b-5p expression than neonates (63.0- and 40.2fold, respectively).

let-7 is an important miRNA family consisting of 13 members. They are highly conserved across several animal species (39). The role of let-7 family members in tumor suppression is well established, and their role in the regulation of innate immunity is slowly being unveiled. Teng et al. have shown that let-7b regulates the expression of TLR4 via posttranscriptional suppression and subsequently influences the activation of NF- $\kappa$ B and downstream gene expression (40). Type 1 IFN production and antiviral signaling cascades are an important defense mechanism in the innate immune response to viral infections. let-7b has also been shown to regulate type 1 IFN production and can inhibit HCV replication and viral protein translation through insulin-like growth factor 2 mRNA-binding protein 1 (41-43). Whether diminished let-7b expression in neonatal leukocyte subsets can lead to altered type 1 IFN production and the susceptibility of newborns to viral infections need further investigation $(1,29)$. In our study, let$7 \mathrm{~b}-5 \mathrm{p}$ modulated IL- 6 and TNF- $\alpha$ production by monocytes. It has been suggested that, with LPS stimulation, hepatocarcinoma cells transfect let-7b enriched microparticles into macrophages, resulting in IL-6 downregulation in macrophages (44). We observed that more abundant let-7b expression in adult monocytes corresponded to lower IL-6 production than in CB monocytes with LPS stimulation. Transfection of adult monocytes 
A

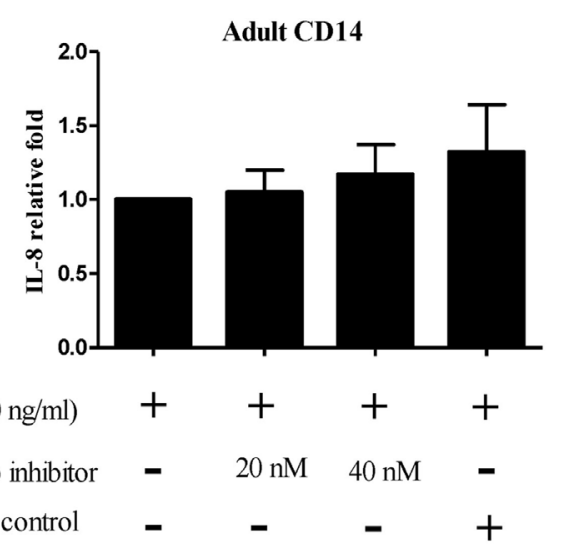

B

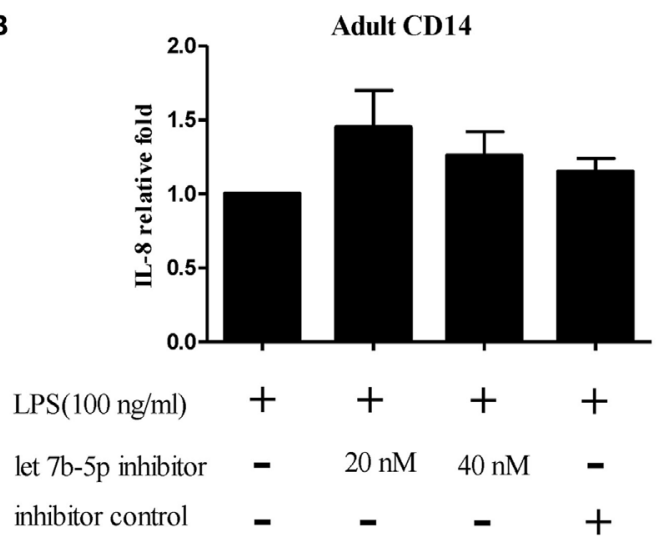

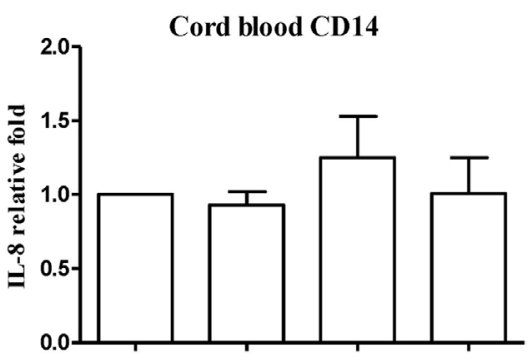

$\operatorname{LPS}(100 \mathrm{ng} / \mathrm{ml}) \quad+\quad+\quad+\quad+$

let 7b-5p mimic - $\quad 20 \mathrm{nM} \quad 40 \mathrm{nM} \quad$ -

mimic control - $\quad$ - $\quad$ - $\quad+$

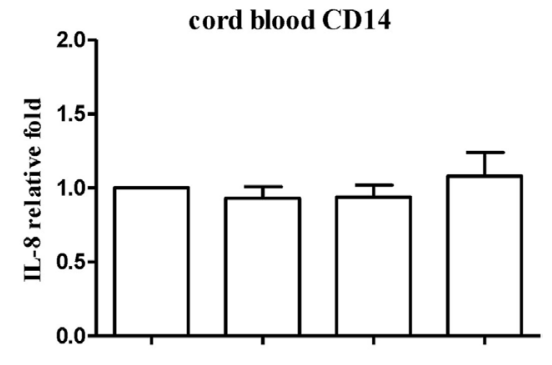

FIGURE 15 | The effect of let-7b-5p on interleukin (IL)-8 production by monocytes. Adult monocytes with or without let-7b-5p inhibitor transfection and cord blood monocytes with or without let-7b-5p mimic transfection were subjected to detection of the IL-8 protein after LPS stimulation for $16 \mathrm{~h}$. The transfection times were (A) $24 \mathrm{~h}$ and (B) $48 \mathrm{~h}$. IL-8 production is represented as relative fold expression compared to the LPS stimulation control. * $p<0.05$ as compared with LPS stimulation only with Mann-Whitney $U$ test $(n=5)$.

with a let-7b-5p inhibitor enhanced IL-6 production, while transfection of a let-7b-5p mimic into CB monocytes suppressed IL-6 production. This suggests that reduced let- $7 \mathrm{~b}$ expression in CB monocytes contributes to higher IL-6 production, compared to adult monocytes. Since IL-6 can modulate the recruitment and differentiation of $\mathrm{T}$ and $\mathrm{B}$ lymphocytes (45), let-7b plays an important modulatory role in the altered immune responses in newborns.

Interleukin- 6 is a multifunctional cytokine secreted by many kinds of cells. IL-6 is produced in response to TLR ligands and other pro-inflammatory cytokines through the NF- $\mathrm{\kappa B}$ signaling pathway (45). Although let-7b was also reported to target TLR4 and suppress IL-8 production through NF- $\mathrm{KB}$ regulation in gastric epithelial cells with Helicobacter pylori infection (40), there are likely different mechanisms for IL-6/IL-8 production control in specific cells, as let-7b cannot influence IL-8 production in both adult and $\mathrm{CB}$ monocytes.

Neonates are susceptible to infection, and neonatal sepsis is a significant cause of mortality and morbidity in newborns (46). Inflammatory responses are necessary for the host to respond to components of invading organisms. At the early stages of infection,
TNF- $\alpha$, IL- $1 \beta$, IL- 6 , and IL-8 pro-inflammatory cytokines are produced and stimulate immune cells leading to activation of an inflammatory cascade (47). The subsequent inflammatory cascade includes many biologically active mediators and can induce a systemic inflammatory response. The inflammatory response is thereafter counteracted by anti-inflammatory mediators to restore immunological homeostasis. Excessive pro-inflammatory mediators or inadequate anti-inflammatory responses will lead to sepsis (47). In addition to antibiotics, other adjuvant therapies primarily target the dysregulated innate immune response. Pentoxifylline, a xanthine-derived phosphodiesterase inhibitor that decreases TNF- $\alpha$ and IL- 6 production, has been reported to improve the clinical outcome of preterm sepsis (48). Recently, anti-cytokine agents in early sepsis with excessive uncontrolled hyper-inflammatory state have been addressed (49). Riedemann et al. demonstrated that an anti-IL-6 antibody could significantly improve survival through reduction of $\mathrm{C} 5 \mathrm{aR}$ in various organs in a cecal ligation/puncture model in mice (50). Remick et al. also showed that the combination of IL-1 receptor antagonist and TNF soluble receptor is also effective in this clinically relevant mouse model of sepsis (51). Although each strategy has certain benefits, 
there is still controversy regarding the general clinical application and potential side effects. Since transfection of let-7b-5p mimic could suppress IL- 6 and TNF- $\alpha$ production of CB monocytes, regulation of let- $7 b-5 p$ has the potential to play a role in neonatal sepsis control.

In conclusion, we demonstrate systematic and functional miRNA profiles of neonate and adult leukocyte subsets. We show that all adult leukocyte subsets have higher let-7b-5p expression than the corresponding CB leukocytes. let-7b-5p negatively regulates the production of IL- 6 and TNF- $\alpha$ by human monocytes. Our study supports a comprehensive miRNA transcriptome database of neonatal immune cells and serves as a valuable resource for elucidating the role of miRNA-mediated regulation in neonatal immunity.

\section{AUTHOR CONTRIBUTIONS}

H-RY, T-YH, H-CH, H-CK, and S-CL contributed to designed the work; H-RY, T-YH, H-CH, H-CK, S-CL, and K-SH contributed to data acquisition; H-RY, T-YH, H-CH, H-CK, and S-CL performed data analysis and interpretation; $\mathrm{H}-\mathrm{RY}, \mathrm{KY}$, and $\mathrm{K}-\mathrm{SH}$ drafted the manuscript; H-RY and T-YH finalized the article. All

\section{REFERENCES}

1. Yu HR, Huang YC, Yang KD. Neonatal varicella frequently associated with visceral complications: a retrospective analysis. Acta Paediatr Taiwan (2003) 44(1):25-8.

2. Yang KD, Hill HR. Immune responses to infectious diseases: an evolutionary perspective. Pediatr Infect Dis J (1996) 15(4):355-64. doi:10.1097/ 00006454-199604000-00015

3. Yu HR, Chang JC, Chen RF, Chuang H, Hong KC, Wang L, et al. Different antigens trigger different $\mathrm{Th} 1 / \mathrm{Th} 2$ reactions in neonatal mononuclear cells (MNCs) relating to T-bet/GATA-3 expression. J Leukoc Biol (2003) 74(5):952-8. doi:10.1189/jlb.0902474

4. Hou PC, Yu HR, Kuo HC, Wang L, Lin LY, Sheen JM, et al. Different modulating effects of adenosine on neonatal and adult polymorphonuclear leukocytes. ScientificWorldJournal (2012) 2012:387923. doi: $10.1100 / 2012 / 387923$

5. Goldmann DA. Prevention and management of neonatal infections. Infect Dis Clin North Am (1989) 3(4):779-813.

6. Yu HR, Kuo HC, Huang HC, Kuo HC, Chen TY, Huang LT, et al. Identification of immunodeficient molecules in neonatal mononuclear cells by proteomic differential displays. Proteomics (2011) 11(17):3491-500. doi:10.1002/ pmic. 201100123

7. Yu HR, Kuo HC, Huang LT, Chen CC, Tain YL, Sheen JM, et al. L-Arginine modulates neonatal lymphocyte proliferation through an interleukin-2 independent pathway. Immunology (2014) 143(2):184-92. doi:10.1111/ imm. 12300

8. Hilkens CM, Vermeulen H, van Neerven RJ, Snijdewint FG, Wierenga EA, Kapsenberg ML. Differential modulation of T helper type 1 (Th1) and T helper type 2 (Th2) cytokine secretion by prostaglandin E2 critically depends on interleukin-2. Eur J Immunol (1995) 25(1):59-63. doi:10.1002/eji. 1830250112

9. Roth I, Corry DB, Locksley RM, Abrams JS, Litton MJ, Fisher SJ. Human placental cytotrophoblasts produce the immunosuppressive cytokine interleukin 10. J Exp Med (1996) 184(2):539-48. doi:10.1084/jem.184.2.539

10. Piccinni MP, Giudizi MG, Biagiotti R, Beloni L, Giannarini L, Sampognaro $\mathrm{S}$, et al. Progesterone favors the development of human $\mathrm{T}$ helper cells producing Th2-type cytokines and promotes both IL-4 production and membrane CD30 expression in established Th1 cell clones. J Immunol (1995) 155(1):128-33. the authors have read and approved the final manuscript and agreed to be accountable for all aspects of the work.

\section{FUNDING}

This study was supported in part by grants CMRPG8D1402 (H-RY), NSC 102-2314-B-182-066-MY3 (H-RY), and MOST 105-2314-B-182-051-MY2 from the Ministry of Science and Technology, Taiwan. We thank the Genomics \& Proteomics Core Laboratory, Department of Medical Research, Kaohsiung Chang Gung Memorial Hospital for technical supports.

\section{SUPPLEMENTARY MATERIAL}

The Supplementary Material for this article can be found online at http://journal.frontiersin.org/article/10.3389/fimmu. 2016.00615/full\#supplementary-material.

FIGURE S1 | Transfection of let-7b-5p inhibitor and mimic into adult and cord blood (CB) monocytes, respectively. (A) Transfection of the let-7b-5p inhibitor into adult monocytes suppressed the expression of let-7b-5p.

(B) Transfection of let-7b-5p mimic into CB monocytes enhanced the expression of let-7b-5p.

11. Yu HR, Chen RF, Hong KC, Bong CN, Lee WI, Kuo HC, et al. IL-12 independent Th1 polarization in human mononuclear cells infected with varicella-zoster virus. Eur J Immunol (2005) 35(12):3664-72. doi:10.1002/ eji.200526258

12. Yu HR, Kuo HC, Huang HC, Huang LT, Tain YL, Chen CC, et al. Glyceraldehyde-3-phosphate dehydrogenase is a reliable internal control in western blot analysis of leukocyte subpopulations from children. Anal Biochem (2011) 413(1):24-9. doi:10.1016/j.ab.2011.01.037

13. Bartel DP. microRNAs: genomics, biogenesis, mechanism, and function. Cell (2004) 116(2):281-97. doi:10.1016/S0092-8674(04)00045-5

14. Slezak-Prochazka I, Durmus S, Kroesen BJ, van den Berg A. microRNAs, macrocontrol: regulation of miRNA processing. RNA (2010) 16(6):1087-95. doi:10.1261/rna.1804410

15. O'Connell RM, Rao DS, Chaudhuri AA, Baltimore D. Physiological and pathological roles for microRNAs in the immune system. Nat Rev Immunol (2010) 10(2):111-22. doi:10.1038/nri2708

16. Navarro F, Lieberman J. Small RNAs guide hematopoietic cell differentiation and function. J Immunol (2010) 184(11):5939-47. doi:10.4049/ jimmunol.0902567

17. Lindsay MA. microRNAs and the immune response. Trends Immunol (2008) 29(7):343-51. doi:10.1016/j.it.2008.04.004

18. Liu G, Abraham E. microRNAs in immune response and macrophage polarization. Arterioscler Thromb Vasc Biol (2013) 33(2):170-7. doi:10.1161/ ATVBAHA.112.300068

19. Xiao C, Rajewsky K. microRNA control in the immune system: basic principles. Cell (2009) 136(1):26-36. doi:10.1016/j.cell.2008.12.027

20. Weitzel RP, Lesniewski ML, Haviernik P, Kadereit S, Leahy P, Greco NJ, et al. microRNA 184 regulates expression of NFAT1 in umbilical cord blood CD4+ T cells. Blood (2009) 113(26):6648-57. doi:10.1182/blood-2008-09181156

21. Lederhuber H, Baer K, Altiok I, Sadeghi K, Herkner KR, Kasper DC. microRNA-146: tiny player in neonatal innate immunity? Neonatology (2011) 99(1):51-6. doi:10.1159/000301938

22. Charrier E, Cordeiro P, Cordeau M, Dardari R, Michaud A, Harnois M, et al. Post-transcriptional down-regulation of toll-like receptor signaling pathway in umbilical cord blood plasmacytoid dendritic cells. Cell Immunol (2012) 276(1-2):114-21. doi:10.1016/j.cellimm.2012.04.010

23. Huang HC, Yu HR, Huang LT, Huang HC, Chen RF, Lin IC, et al. miRNA-125b regulates TNF-alpha production in CD14+ neonatal monocytes via 
post-transcriptional regulation. J Leukoc Biol (2012) 92(1):171-82. doi:10.1189/ jlb.1211593

24. Chen HC, Lee YS, Sieber M, Lu HT, Wei PC, Wang CN, et al. microRNA and messenger RNA analyses of mesenchymal stem cells derived from teeth and the Wharton jelly of umbilical cord. Stem Cells Dev (2012) 21(6):911-22. doi:10.1089/scd.2011.0186

25. Allantaz F, Cheng DT, Bergauer T, Ravindran P, Rossier MF, Ebeling M, et al. Expression profiling of human immune cell subsets identifies miRNA-mRNA regulatory relationships correlated with cell type specific expression. PLoS One (2012) 7(1):e29979. doi:10.1371/journal.pone.0029979

26. Zhan M, Miller CP, Papayannopoulou T, Stamatoyannopoulos G, Song CZ. microRNA expression dynamics during murine and human erythroid differentiation. Exp Hematol (2007) 35(7):1015-25. doi:10.1016/ j.exphem.2007.03.014

27. Wang Y, Zhao GX, Xu LH, Liu KP, Pan H, He J, et al. Cucurbitacin IIb exhibits anti-inflammatory activity through modulating multiple cellular behaviors of mouse lymphocytes. PLoS One (2014) 9(2):e89751. doi:10.1371/journal. pone. 0089751

28. Chen J, Liu Z, Yang Y. In vitro screening of LPS-induced miRNAs in leukocytes derived from cord blood and their possible roles in regulating TLR signals. Pediatr Res (2014) 75(5):595-602. doi:10.1038/pr.2014.18

29. Yu HR, Huang HC, Kuo HC, Sheen JM, Ou CY, Hsu TY, et al. IFN-alpha production by human mononuclear cells infected with varicella-zoster virus through TLR9-dependent and -independent pathways. Cell Mol Immunol (2011) 8(2):181-8. doi:10.1038/cmi.2010.84

30. Chan SH, Wu CW, Li AF, Chi CW, Lin WC. miR-21 microRNA expression in human gastric carcinomas and its clinical association. Anticancer Res (2008) 28(2A):907-11.

31. Yu HR, Kuo HC, Chen CC, Sheen JM, Tiao MM, Chen YC, et al. Prenatal dexamethasone exposure in rats results in long-term epigenetic histone modifications and tumour necrosis factor-alpha production decrease. Immunology (2014) 143(4):651-60. doi:10.1111/imm.12346

32. Gao Y, Flori L, Lecardonnel J, Esquerre D, Hu ZL, Teillaud A, et al. Transcriptome analysis of porcine PBMCs after in vitro stimulation by LPS or PMA/ionomycin using an expression array targeting the pig immune response. BMC Genomics (2010) 11:292. doi:10.1186/1471-2164-11-292

33. Wells CA, Ravasi T, Faulkner GJ, Carninci P, Okazaki Y, Hayashizaki Y, et al. Genetic control of the innate immune response. BMC Immunol (2003) 4:5. doi:10.1186/1471-2172-4-5

34. Sharon N, Lis H. History of lectins: from hemagglutinins to biological recognition molecules. Glycobiology (2004) 14(11):53R-62R. doi:10.1093/glycob/ cwh122

35. Palin AC, Ramachandran V, Acharya S, Lewis DB. Human neonatal naive $\mathrm{CD} 4+\mathrm{T}$ cells have enhanced activation-dependent signaling regulated by the microRNA miR-181a. J Immunol (2013) 190(6):2682-91. doi:10.4049/ jimmunol.1202534

36. Merkerova M, Vasikova A, Belickova M, Bruchova H. microRNA expression profiles in umbilical cord blood cell lineages. Stem Cells Dev (2010) 19(1):17-26. doi:10.1089/scd.2009.0071

37. Takahashi N, Nakaoka T, Yamashita N. Profiling of immune-related microRNA expression in human cord blood and adult peripheral blood cells upon proinflammatory stimulation. Eur J Haematol (2012) 88(1):31-8. doi:10.1111/j.1600-0609.2011.01707.x

38. Noh SJ, Miller SH, Lee YT, Goh SH, Marincola FM, Stroncek DF, et al. let-7 microRNAs are developmentally regulated in circulating human erythroid cells. J Transl Med (2009) 7:98. doi:10.1186/1479-5876-7-98
39. Pasquinelli AE, Reinhart BJ, Slack F, Martindale MQ, Kuroda MI, Maller B, et al. Conservation of the sequence and temporal expression of let-7 heterochronic regulatory RNA. Nature (2000) 408(6808):86-9. doi:10.1038/35040556

40. Teng GG, Wang WH, Dai Y, Wang SJ, Chu YX, Li J. let-7b is involved in the inflammation and immune responses associated with Helicobacter pylori infection by targeting toll-like receptor 4. PLoS One (2013) 8(2):e56709. doi:10.1371/journal.pone.0056709

41. Cheng JC, Yeh YJ, Tseng CP, Hsu SD, Chang YL, Sakamoto N, et al. let-7b is a novel regulator of hepatitis C virus replication. Cell Mol Life Sci (2012) 69(15):2621-33. doi:10.1007/s00018-012-0940-6

42. Conrad KD, Niepmann M. The role of microRNAs in hepatitis C virus RNA replication. Arch Virol (2014) 159(5):849-62. doi:10.1007/ s00705-013-1883-4

43. Cheng M, Si Y, Niu Y, Liu X, Li X, Zhao J, et al. High-throughput profiling of alpha interferon- and interleukin-28B-regulated microRNAs and identification of let-7s with anti-hepatitis $\mathrm{C}$ virus activity by targeting IGF2BP1.J Virol (2013) 87(17):9707-18. doi:10.1128/JVI.00802-13

44. Li D, Jia H, Zhang H, Lv M, Liu J, Zhang Y, et al. TLR4 signaling induces the release of microparticles by tumor cells that regulate inflammatory cytokine IL-6 of macrophages via microRNA let-7b. Oncoimmunology (2012) 1(5):687-93. doi:10.4161/onci.19854

45. Scheller J, Chalaris A, Schmidt-Arras D, Rose-John S. The pro- and antiinflammatory properties of the cytokine interleukin-6. Biochim Biophys Acta (2011) 1813(5):878-88. doi:10.1016/j.bbamcr.2011.01.034

46. Stoll BJ. The global impact of neonatal infection. Clin Perinatol (1997) 24(1):1-21.

47. Machado JR, Soave DF, da Silva MV, de Menezes LB, Etchebehere RM, Monteiro ML, et al. Neonatal sepsis and inflammatory mediators. Mediators Inflamm (2014) 2014:269681. doi:10.1155/2014/269681

48. Lauterbach R, Pawlik D, Kowalczyk D, Ksycinski W, Helwich E, Zembala M. Effect of the immunomodulating agent, pentoxifylline, in the treatment of sepsis in prematurely delivered infants: a placebo-controlled, double-blind trial. Crit Care Med (1999) 27(4):807-14. doi:10.1097/00003246-19990400000042

49. Hotchkiss RS, Karl IE. Cytokine blockade in sepsis - are two better than one? Crit Care Med (2001) 29(3):671-2. doi:10.1097/00003246-200103000-00040

50. Riedemann NC, Neff TA, Guo RF, Bernacki KD, Laudes IJ, Sarma JV, et al. Protective effects of IL-6 blockade in sepsis are linked to reduced C5a receptor expression. J Immunol (2003) 170(1):503-7. doi:10.4049/jimmunol. 170.1.503

51. Remick DG, Call DR, Ebong SJ, Newcomb DE, Nybom P, Nemzek JA, et al. Combination immunotherapy with soluble tumor necrosis factor receptors plus interleukin 1 receptor antagonist decreases sepsis mortality. Crit Care Med (2001) 29(3):473-81. doi:10.1097/00003246-200103000-00001

Conflict of Interest Statement: The authors declare that the research was conducted in the absence of any commercial or financial relationships that could be construed as a potential conflict of interest.

Copyright $\odot 2016 \mathrm{Yu}, \mathrm{Hsu}$, Huang, Kuo, Li, Yang and Hsieh. This is an open-access article distributed under the terms of the Creative Commons Attribution License (CC $B Y)$. The use, distribution or reproduction in other forums is permitted, provided the original author(s) or licensor are credited and that the original publication in this journal is cited, in accordance with accepted academic practice. No use, distribution or reproduction is permitted which does not comply with these terms. 